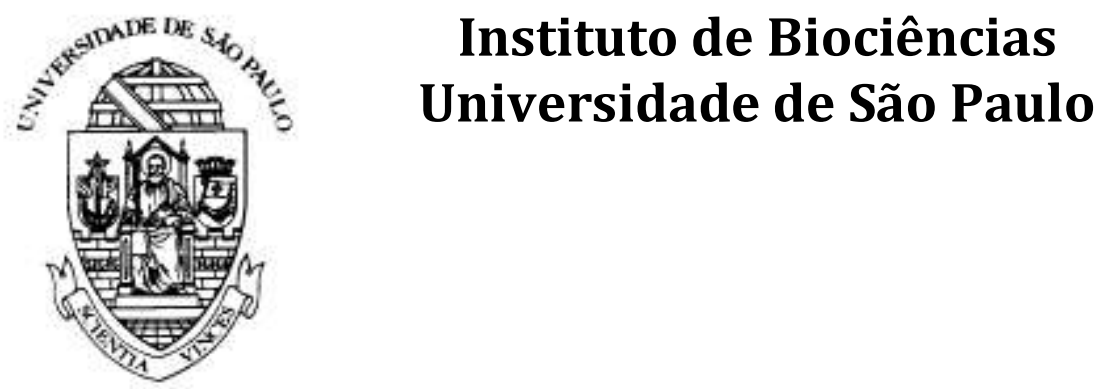

Instituto de Biociências
Universidade de São Paulo

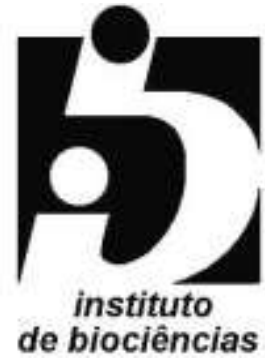

Caracterização da variabilidade fenotípica em um modelo animal para Síndrome de Marfan

Bruno Lazzari de Lima

São Paulo

2011 
Bruno Lazzari de Lima

\section{Caracterização da variabilidade fenotípica em um modelo animal para Síndrome de Marfan}

\section{Characterization of the phenotypic variability in a mouse model for Marfan Syndrome}

Tese apresentada ao Instituto de Biociências da Universidade de São Paulo, para a obtenção de Título de Doutor em Ciências, na Área de Biologia / Genética.

Orientadora: Dra. Lygia da Veiga Pereira Carramaschi. 
Lima, Bruno Lazzari de

Caracterização da variabilidade fenotípica em um modelo animal para Síndrome de Marfan.

114 páginas

Tese de Doutorado - Instituto de Biociências da Universidade de São Paulo. Departamento de Genética e Biologia Evolutiva. Área de concentração: Biologia/Genética

1. Síndrome de Marfan 2. Fibrilina-1 3. Modelos animais

Universidade de São Paulo. Instituto de Biociências. Departamento de Genética e Biologia Evolutiva 
Dedico este trabalho,

- aos meus pais, Ana Maria e João Antônio, por sempre estarem presentes para me ouvir, aconselhar e incentivar em todos os momentos da minha vida;

- à minha tia e madrinha Marcia Cristina, minha segunda mãe. 
AGRADECIMENTOS 
Meus sinceros votos de agradecimento,

Aos meus pais, meus orientadores na vida. Por toda sua dedicação, carinho, apoio e tudo aquilo que somente pais podem nos dar. Pela sua paciência nos meus momentos de estresse, pelas palavras certas nos momentos difíceis e por sempre estarem lá. Pelo beijinho de boa noite, pelo dinheirinho da balada, pela ajuda na lição de casa, pelo passeio do final de semana...

À Dra. Lygia, pela oportunidade de realizar esse projeto. Pela sua paciência, dedicação e conhecimentos repassados durante todo o desenvolvimento do mesmo. Foi muito bom trabalhar com alguém que tem tanta empolgação com aquilo que faz.

À Dra. Mariz Vainzof, minha madrinha dentro da ciência, tendo me ajudado e contribuído para o meu desenvolvimento desde o princípio da minha carreira acadêmica.

Aos demais professores do departamento de genética e biologia evolutiva, pelos conhecimentos compartilhados.

À Dra Silvia pela sua colaboração com a manutenção dos animais, tão importantes para o desenvolvimento deste projeto, e por toda sua ajuda.

À minha tia Marcia Cristina, sem dúvida nenhuma, a principal influência para que eu quisesse um dia me tornar um doutor. E por todos os inesquecíveis momentos da minha vida.

Aos meus familiares, tio Jose, tia Vera e tio Silvio, meus primos Thiago, André, Carolina, Rodrigo, Virginia, Guilherme e Henrique, meu avô Antônio e minha avó Gentil (i.m.) Por serem alguns dos pilares da minha vida.

Aos meus antigos amigos de faculdade, em especial ao Alex, Marcelo (Sinhá), Vitor Hugo (Vitão), Gledsley (Gepeto), Bruno (Nelas), Natale (Nani), Ana, Sabrina (Timão). Por todos os momentos alegres e divertidos, que são tão importantes na vida de uma pessoa.

À Natássia, uma pessoa muito especial na minha vida. Pelo seu companheirismo e por toda a sua colaboração pessoal e profissional durante todos esses anos.

A todos os meus colegas de laboratório que, de alguma maneira, sempre colaboraram e me ajudaram. Em especial ao Gustavo, pela sua fundamental colaboração neste trabalho, e à Ana Maria, Joana, Érica e Raquel, pelas conversas e conselhos.

A todos os meus colegas de departamento, vizinhos de laboratório e funcionários do IB-USP.

Aos meus novos amigos, em especial à Camila, Fernanda Donata, Fernanda Raquel, Flavio, João, Larissa, Manuela, Marcelle, Micheli, Natália, Priscilla, Rafael, Taísa, Waleska e Kalana. Passar as manhãs com vocês me mantém feliz pelo resto do dia.

À Laura, que mesmo estando a tão pouco tempo na minha vida, tem me proporcionado tanto bons e inesquecíveis momentos. Obrigado por tudo que você tem feito, pelo seu carinho e sua paciência.

À Mauy (i.m.), Victória (i.m.), Batata (i.m.), Jeep (i.m.) e Thyla, meus irmãos de quatro patas. "Um cachorro não se importa se você é rico ou pobre, inteligente ou idiota, esperto ou burro... dê seu coração a ele, e ele lhe dará o dele... De quantas pessoas você pode falar isso?" (J. Grogan).

À FAPESP pelo apoio financeiro. 
"A vida é aquilo que acontece enquanto fazemos planos para o futuro." (John Lennon) 


\section{RESUMO}


A Síndrome de Marfan (SMF) é uma doença de tecido conjuntivo, com caráter autossômico dominante, que acomete cerca de 1 em 5.000 indivíduos. As principais manifestações clínicas incluem aneurismas e rompimento da aorta, crescimento excessivo dos ossos, escoliose e deformidades torácicas. Mutações no gene FBN1, que codifica a proteína de matriz extracelular fibrilina-1, foram relacionadas à doença, fazendo com que essa fosse classificada no grupo das fibrilinopatias. Mais de 500 mutações já foram identificadas e, com exceção de um pequeno grupo de mutações recorrentes, as mutações são únicas, sendo encontradas em famílias isoladas. A doença caracteriza-se pela grande variabilidade tanto intra quanto interfamilial, não sendo possível fazer uma correlação precisa entre genótipo e fenótipo. Este trabalho visa discutir os mecanismos responsáveis pela variabilidade clínica inter e intra familiar da SMF através da caracterização qualitativa e quantitativa da variabilidade fenotípica observada no modelo murino para SMF $\mathrm{mg} \Delta^{\text {loxPneo }}$. Neste sentido, caracterizamos o modelo $\mathrm{mg} \Delta^{\text {loxPneo }} \mathrm{em}$ duas linhagens de camundongos diferentes, C57BL/6 e 129/Sv. Os animais mutantes de ambas as linhagens apresentaram deficiência na deposição de microfibrilas, cifose de coluna, enfisema pulmonar e degeneração da parede aórtica. Contudo, a idade de início dos sinais fenotípicos mostrou-se mais tardia em animais da linhagem C57BL/6 em comparação com os animais 129/Sv, indicando a presença de genes modificadores entre as duas linhagens. Além disso, caracterizamos uma grande variabilidade fenotípica entre os animais $129 / \mathrm{Sv}$ mutantes, o que é sugestivo do envolvimento de fatores epigenéticos na gravidade da doença. Finalmente, demonstramos uma forte correlação negativa entre os níveis globais de transcrição do gene Fbn1 e a gravidade do fenótipo. Esses resultados corroboram a hipótese de que o nível de expressão da proteína normal está relacionado com a gravidade do quadro clínico da SMF em humanos. Com base nisso, o trabalho também visa o estudo de novas estratégias terapêuticas para a SMF nesse mesmo modelo. 
The Marfan syndrome (MFS) is an autosomal dominant disease of connective tissue, which affects 1 in 5,000 individuals. The main clinical manifestations include aneurysms and aortic disruption, excessive growth of bones, scoliosis and thoracic deformities. Mutations in the FBN1 gene, which encodes the fibrillin-1 protein, were genetically linked to the MFS, classifying this disease in the fibrilinopathies group. Over 500 mutations have been identified and, except for a small group of recurrent mutations, the mutations are unique, being found in unrelated families. The disease is characterized by a wide clinical variability both within and between families, and it is not possible to make a precise genotypephenotype correlation. This work concerns the analysis of the mechanisms associated with the clinical variability present within and between MFS families, by qualitative and quantitative characterization of the phenotypic variability observed in the $\mathrm{mg} \Delta^{\text {loxPneo }}$ model for MFS. We characterize the model $\mathrm{mg} \Delta^{\text {loxPneo }}$, in two different mouse strains, the C57BL/ 6 and the 129/Sv strain. Mutant animals from both strains present defective microfibrillar deposition, emphysema, deterioration of aortic wall and kyphosis. However, the onset of a clinical phenotypes is earlier in the 129/Sv than in C57BL/6 background, indicating the existence of genetic modifiers of MFS between these two mouse strains. In addition, we characterized a wide clinical variability within the 129/Sv heterozygotes, suggesting involvement of epigenetic factors in disease severity. Finally, we show a strong negative correlation between overall levels of Fbn1 expression and the severity of the phenotypes. These results corroborated with studies, using animal models, as well with MFS patients, where the levels of normal fibrillin-1 seem to have the potential to modulate the clinical severity of the disease. In addition, the study also aims to evaluate new treatment possibilities for MFS in this same model. 


\section{SUMÁRIO}

I. INTRODUÇÃO ......................................................................................17

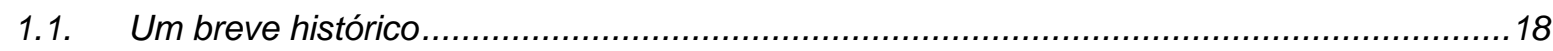

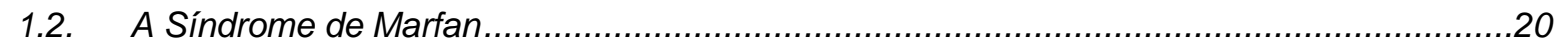

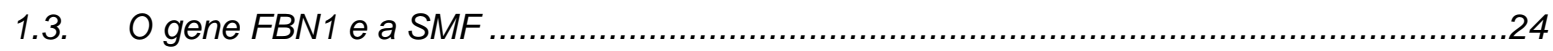

1.4. A Fibrilina-1 e os possíveis mecanismos patogênicos .................................................25

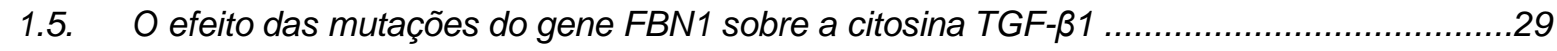

1.6. As proteínas associadas à via de sinalização de TGF- $\beta 1$................................................

1.7. A utilização de fármacos no tratamento da síndrome de Marfan ........................................33

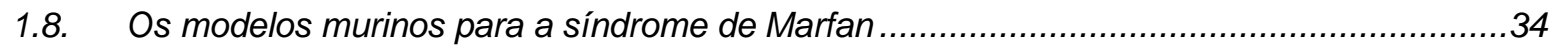

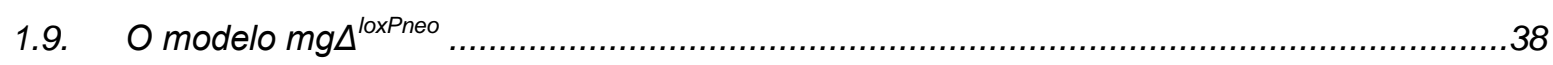

II. OBJETIVOS ..............................................................................................42

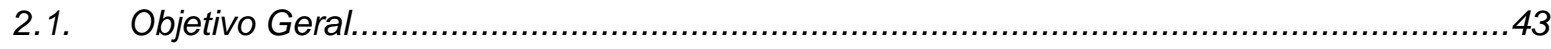

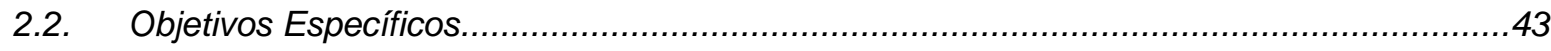

III. MATERIAL E MÉTODOS .............................................................................44

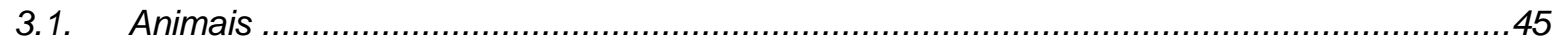

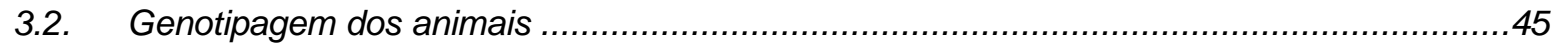

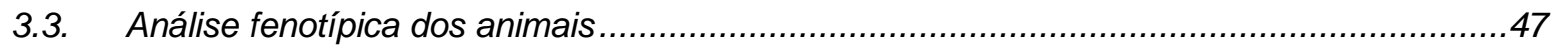

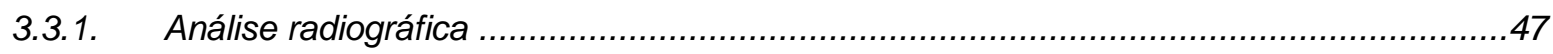

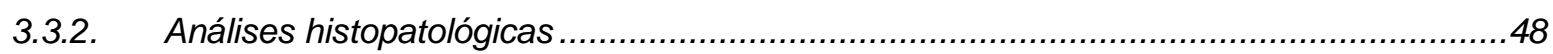

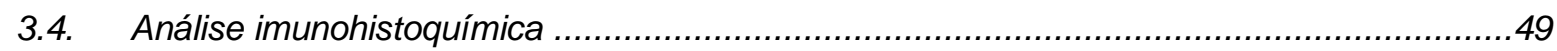

3.5. Administração da droga Ramipril em animais heterozigotos da linhagem C57BL/6...........49

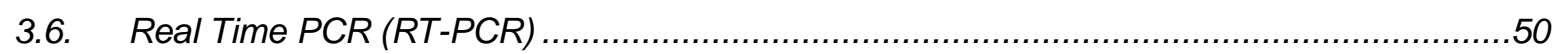

3.7. Western-Blot para o estudo da proteína phospho-smad2 ...............................................51

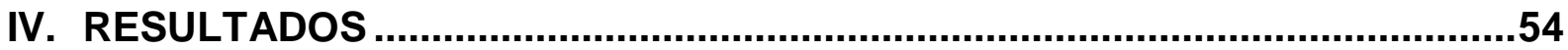

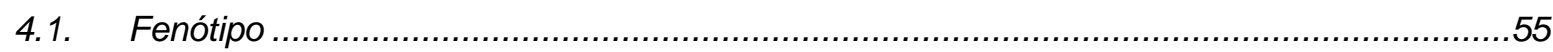

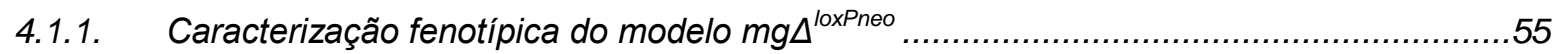

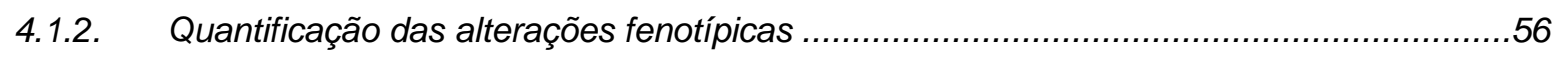

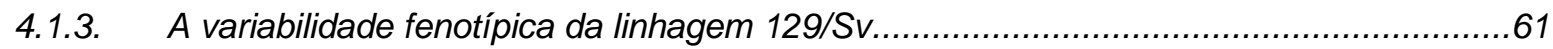

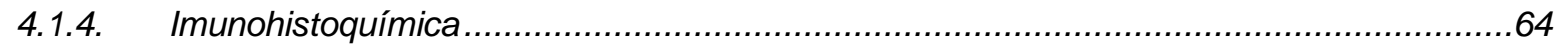

4.2. Análise dos níveis de transcrição do gene Fbn1 por Real Time PCR (RT-PCR) ...............66

4.2.1. Comparação da transcrição do alelo Fbn1 x Fbn $1^{\text {mgdloxPneo }}$ em fibroblastos fetais............66

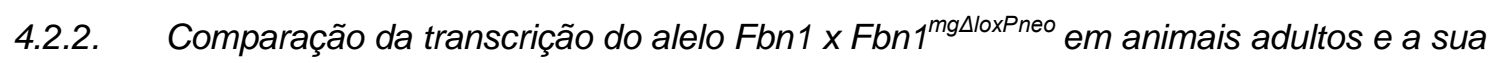
correlação com a variação de fenótipo 
4.2.2.1. A diferença de transcrição entre as linhagens C57BL/6 e 129/Sv .....

4.2.2.2. A relação entre a variação de transcrição do gene Fbn1 com a idade.

4.2.2.3. Comparação da transcrição do gene Fbn1 entre animais da linhagem 129/Sv com diferentes fenótipos.

4.2.3. Efeito da droga Ramipril sobre a transcrição global do gene Fbn1 em animais C57BL/6 mutantes 72

4.3. Avaliação da atividade de TGF- $\beta 1$ nos tecidos afetados

V. DISCUSSÃO

5.1. Caracterização fenotípica do modelo $m g \Delta^{\text {loxPneo }}$ 78

5.2. Avaliação da atividade de TGF- $\beta 1$ nos tecido aórtico e pulmonar do modelo $m g \Delta^{\text {loxPneo }} \ldots . . .80$

5.3. As alterações presentes na imunohistoquímica de fibroblastos fetais em cultura................82

5.4. A diferença fenotípica entre os animais mutantes das linhagens $129 /$ Sv e C57BL/6 ...........83

5.5. A variabilidade fenotípica entre os animais mutantes da linhagem 129/Sv .........................85

5.6. Os mecanismos de patogênese relacionados com a Síndrome de Marfan .........................86

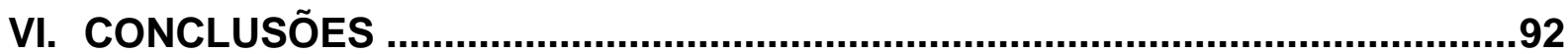

VII. REFERÊNCIAS ..................................................................................95

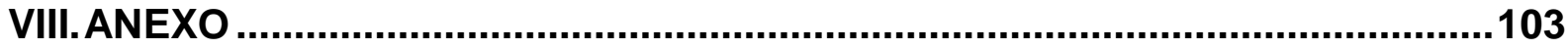




\section{LISTA DE FIGURAS}

FIGURA 1. O pediatra francês Atonine-Bernard Marfan e sua primeira paciente a ser descrita como portadora da dolicoestenomelia, Gabrielle P.

FIGURA 2. Algumas personalidades das quais se suspeita que fossem portadoras da SMF.......

FIGURA 3. Características clínicas mais freqüentes da SMF

FIGURA 4. Cirurgia profilática visando o reparo da aorta por meio da substituição da região do aneurisma por uma prótese.

FIGURA 5. Outras características clínicas da SMF) ..........................................23

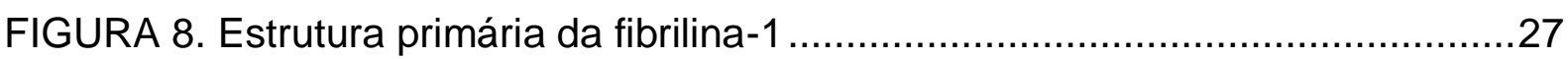

FIGURA 9. A relação entre a fibrilina-1 e a LTBP-1 ..............................................30

FIGURA 10. Representação esquemática para a via de sinalização da citosina TGF$\beta 1$

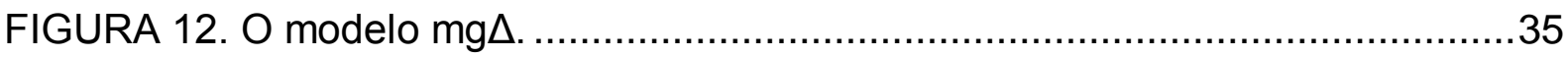

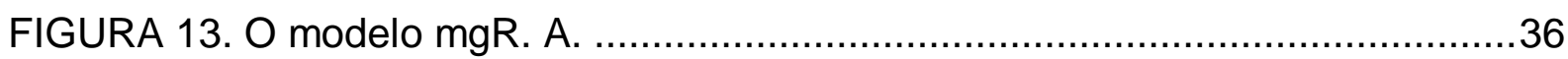

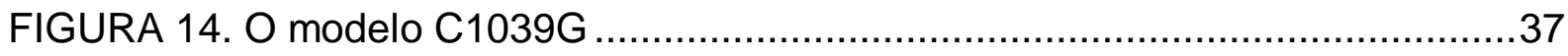

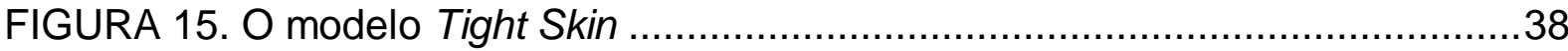

FIGURA 16. Representação esquemática do alelo Fbn $1^{\text {mgDloxPneo }}$............................39

FIGURA 17. Heredograma dos camundongos heterozigotos fundadores da linhagem

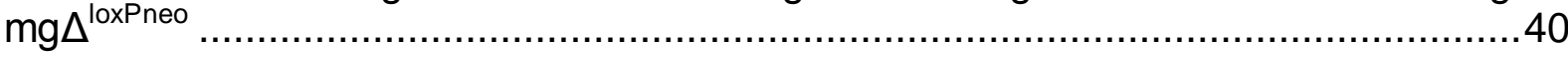

FIGURA 18. Mensurações utilizadas no cálculo de KR. ..........................................47

FIGURA 19. Análise histológica dos pulmões (marcação por HE) .............................57

FIGURA 20. Análise histológica da aorta torácica (coloração de Weigert).................58

FIGURA 21. Análise radiográfica.

FIGURA 22. Gráficos comparativos dos valores de Lm, espessura da parede da aorta (EPA) e KR, entre animais mutantes das linhagens 129/Sv e B6 aos três meses de idade. 
FIGURA 23. Correlação entre a progressão dos fenótipos pulmonar (Lm), aórtico (Espessura da aorta - EPA) e ósseo (KR) com a idade (meses) em animais heterozigotos da linhagem 129/Sv

FIGURA 24. Análise comparativa da variabilidade fenotípica na linhagem 129/Sv...63

FIGURA 25. Variabilidade fenotípica presente na linhagem 129/Sv

FIGURA 26. Imunofluorescência de fibroblastos fetais em cultura, com marcação para fibrilina-1

FIGURA 27. Quantificação relativa dos níveis totais de mRNA do gene Fbn1 em fibroblastos fetais selvagens, heterozigotos e homozigotos por Real Time PCR ......66

FIGURA 28. Quantificação relativa dos níveis totais de mRNA do gene Fbn1 em animais selvagens

FIGURA 29. Quantificação dos níveis mRNA referentes ao alelo selvagem do gene Fbn1 em animais selvagens e mutantes heterozigotos, aos três e seis meses de idade.

FIGURA 30. Correlação entre a transcrição total do gene Fbn1 e a idade de animais B6 e $129 / \mathrm{Sv}$

FIGURA 31. Correlação entre a transcrição do gene $F b n 1$ e a gravidade do fenótipo em animais heterozigotos da linhagem 129/Sv

FIGURA 32. Gráfico comparativo da transcrição do gene Fbn1 em animais B6 selvagens, heterozigotos sem tratamento e heterozigotos tratados com a droga Ramipril .72

FIGURA 33. Análise dos efeitos do tratamento com Ramipril em animais B6 73

FIGURA 34. Western-blot para a proteína phospho-Smad2 (P-smad2) a partir de amostras protéicas pulmonares e aórticas de animais B6 de três e seis meses de idade. 


\section{LISTA DE ABREVIATURAS}

ACE - Angiotensin-converting enzyme.

Ang II - Angiotensina II.

AT1 - Angiotensin receptor type I.

C57BL/6 - B6.

cbEGF - Calcium-binding EGF-precursor-like.

dNTP - desorribonuleotídeo trifosfatado.

EGF - Epidermal growth factor.

EPA - Espessura da parede da aorta.

ERK1 - Extracellular signal-regulated kinase 1.

ERK2 - Extracellular signal-regulated kinase 2.

Het - Heterozigoto.

JNK - C - Jun N - terminal kinase.

Kb - Kilobases.

kDa - Kilodaltons.

KO - Knockout.

$\boldsymbol{K} \boldsymbol{R}$ - Kifosis ratio.

kV - Kilovoltagem.

Lm - Mean linear intercept.

LTBP - Latent TGF- $\beta$ binding protein.

$\mu \mathrm{m}$ - Micrômetro.

mA - Microamperes.

MAPK - MAP Kinases.

MEC - Matriz extracelular.

n - Número.

neoR - Cassete de resistência à neomicina.

ng - Nanogramas.

nm - Nanomolar.

pb - Pares de base.

PBS - Phosphate buffered saline.

PCR - Polimerase chain reaction.

PI3K-Akt - Phosphoinositide 3-kinase-Akt.

P-smad2 - Phospho-Smad2. 
R-Smads - Receptor-regulated Smads.

RT-PCR - Real-Time PCR.

SMF - Síndrome de Marfan.

TGF- $\beta 1$ - Transforming growth factor $\beta 1$.

Tm - Temperatura de melting.

Tsk - Tight Skin.

UV - Ultravioleta.

WT - Wild-type. 
I. INTRODUÇÃO 
1.1. Um breve histórico

Em 1896, Antonine-Bernard Marfan, professor de pediatria em Paris, descreveu uma menina com cinco anos de idade, Gabrielle P (Fig.1), a qual apresentava membros e dedos desproporcionalmente longos e magros, característica denominada por ele como pattes d'araignée ou patas de aranha. A paciente apresentava ainda contraturas nas articulações dos dedos e joelhos, um crânio estreito e alongado (dolicocefalia), além de uma estatura muito elevada para sua idade. Embora seus olhos, coração e intelecto fossem normais, exames radiográficos indicaram a presença de cifoescoliose tóraco-lombar, deformidade na região esternal (pectus excavatum) e enfisema pulmonar (PYERITZ, 2000).

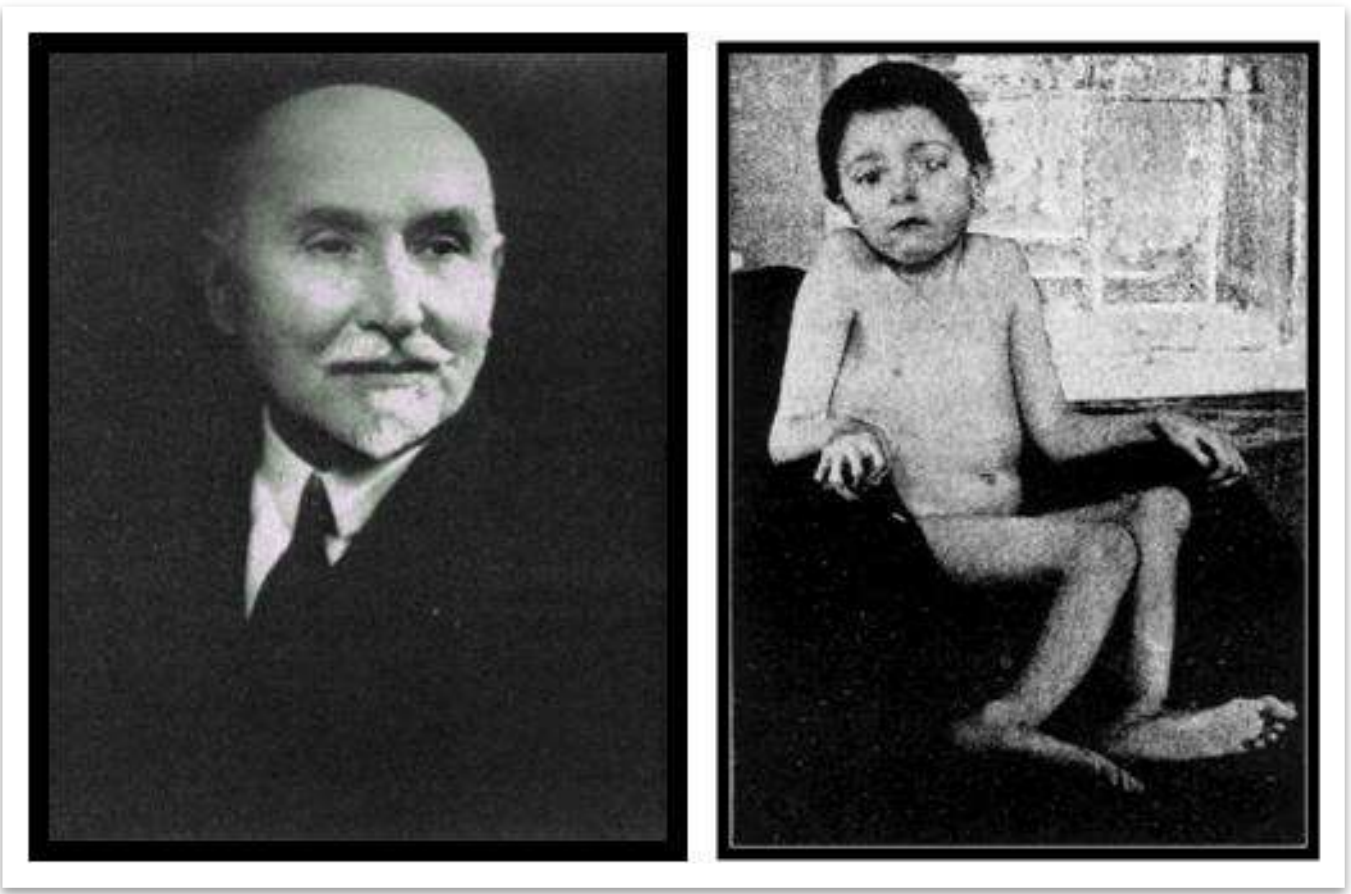

FIGURA 1. O pediatra francês Atonine-Bernard Marfan (esquerda) e sua primeira paciente a ser descrita como portadora da dolicoestenomelia, Gabrielle P (direita) (Fonte: http://www.pifo.uvsq.fr/hebergement/marfan/). 
Em quarenta anos após esse primeiro relato clínico, Marfan avaliou mais de 150 casos similares, os quais foram denominados como dolicoestenomelia, termo preferido pelo médico devido aos membros excessivamente longos. Nessa ocasião, outras alterações associadas já haviam sido reconhecidas, como subluxação do cristalino (ectopia lentis), malformação da valva átrio-ventricular esquerda (valva mitral) e complicações aórticas de dissecação e dilatação (SCHORR et al., 1951). Marfan notou que ambos os sexos eram igualmente afetados, e que as alterações podiam ser recorrentes em gerações seqüenciais de uma mesma família, características compatíveis com um padrão de herança mendeliana dominante (PYERITZ, 2000).

Atualmente, vários atletas jovens morrem por complicações aórticas da Síndrome de Marfan (SMF), alguns dos quais foram diagnosticados somente através de retrospectos clínicos. A morte de uma estrela do voleibol olímpico norteamericano em 1986, Flo Hyman (Fig.2), aumentou a consciência e a informação entre o público geral, atletas, treinadores e médicos ao longo do mundo (BAYLES, 2002). Até os dias de hoje, continua o debate a respeito do diagnóstico de SMF do ex-presidente norte-americano Abraham Lincoln (Fig.2), pois esse era alto, dolicostenomélico e apresentava hiperflexibilidade articular (SCHWARTZ, 1964 ; LATTIMER, 1981). Contudo, casos de personalidades famosas não se restringem aos séculos atuais, pois se acredita que o faraó Akhenaten (Fig.2), o qual governou o Egito antigo de 1350 a 1334 a.C. e fora pai do faraó Tutankhamun, possuísse várias das características relacionadas à síndrome (ALDRED \& SANDISON, 1962). 

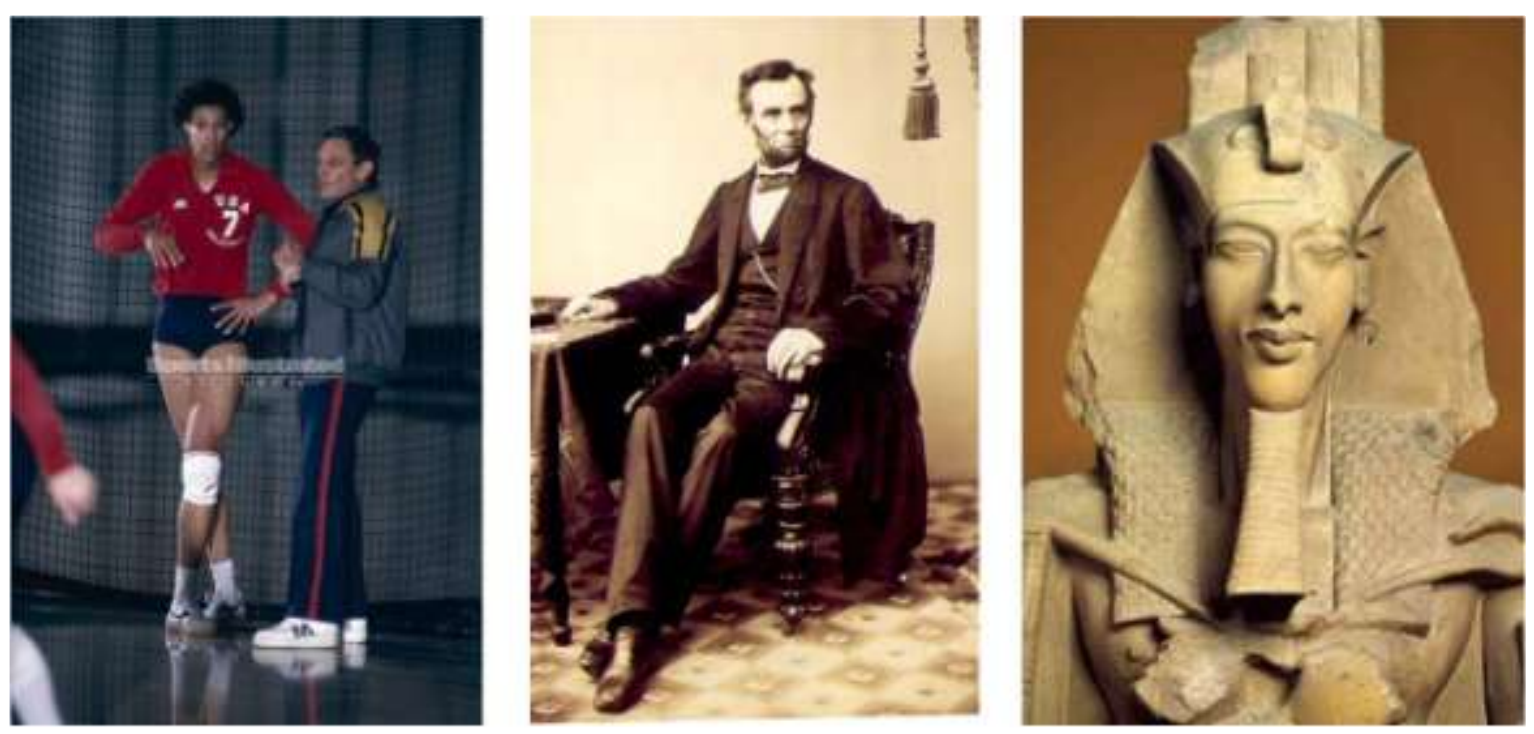

FIGURA 2. Algumas personalidades das quais se suspeita que fossem portadoras da SMF. A jogadora de vôlei norte-americana Flo Hyman (esquerda), o ex-presidente norte-americano Abraham Lincoln (centro) e o faraó Akhenaten (Fonte: http://lewiscrusade.wordpress.com/category/marfansyndrome/).

1.2. A Síndrome de Marfan

A SMF (OMIM 154700) (SCHORDERET, 1991) é uma doença pleitrópica, com manifestações clínicas diversas, e aparentemente independentes, em muitos tecidos e órgãos (PYERITZ, 1989 ; 1993). Trata-se de uma doença com caráter autossômico dominante, que acomete cerca de 1 em 5.000 indivíduos (ADES, 2007). As manifestações clínicas incluem aneurismas e rompimento da aorta, descolamento da retina, subluxação do cristalino, crescimento excessivo dos ossos, hipermobilidade articular, escoliose e deformidades torácicas (Fig.3) (SILVERMAN et al., 1995a ; SILVERMAN et al., 1995b). Essa gama de pleiotropismo vem aumentando devido a intervenções terapêuticas modernas, que possibilitam uma maior longevidade aos indivíduos afetados, permitindo a visualização de 
complicações relacionadas a idades mais avançadas (PYERITZ, 1989 ; LIPSCOMB et al., 1997). A expectativa de vida média dos pacientes tem aumentado significativamente desde 1972, aproximando-se da população geral (ROBINSON et al., 2006).
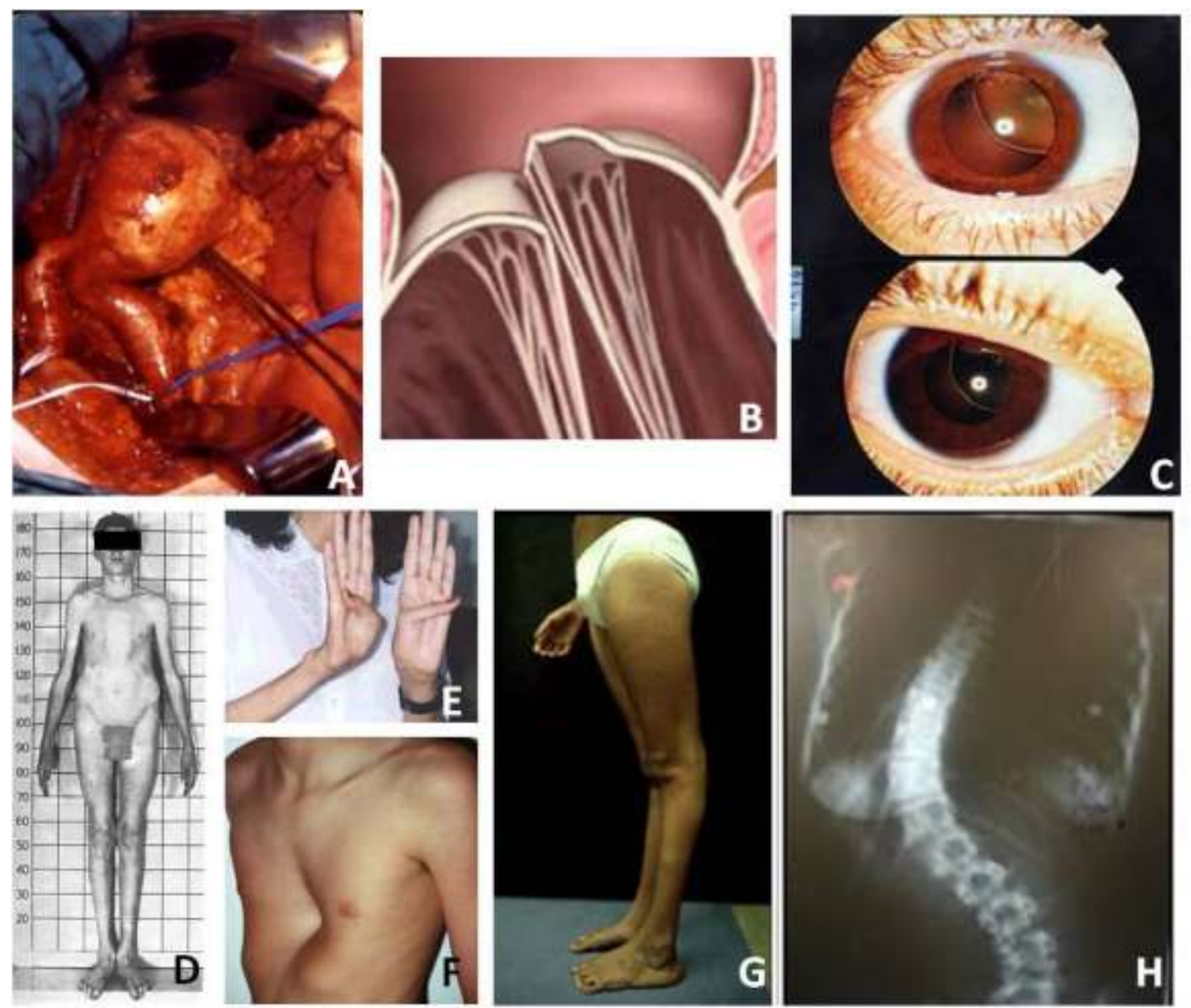

FIGURA 3. Características clínicas mais freqüentes da SMF. A. Aneurisma aórtico (Fonte: http://my.clevelandclinic.org/heart/disorders/aorta_marfan/marfansurgery_actual.aspx); B. Prolapso de valva mitral (Fonte: http://obgyn.med.nyu.edu/conditions-we-treat/conditions/mitral-valve-prolapse); C. Subluxação do cristalino (Fonte: http://www.medstudents.com.br/original/revisao/marfan/); D. Alongamento dos membros (Fonte: http://medicina.ufm.edu/cms/es/SindromedeMarfan); E. Aracnodactilia (Fonte: http://para-leer-algo.blogspot.com/2009/03/sindrome-de-marfan.html); F. Pectus excavatum (Fonte: http://www.nytimes.com/2927Pectusexcavatum.html); G. Hipermobilidade articular (Fonte: http://para-leer-algo.blogspot.com/2009/03/sindrome-de-marfan.html); H. Escoliose (Fonte: http://auladepatologia.wordpress.com/2009/12/). 
Embora algumas intervenções terapêuticas, como a utilização de $\beta$ bloqueadores visando uma diminuição stress hemodinâmico, e cirurgias profiláticas para o reparo da aorta (Fig.4), possibilitem um aumento significativo na expectativa de vida dos pacientes, essas manifestações ainda são responsáveis por uma elevada taxa de mortalidade dos mesmos (SILVERMAN et al., 1995a).

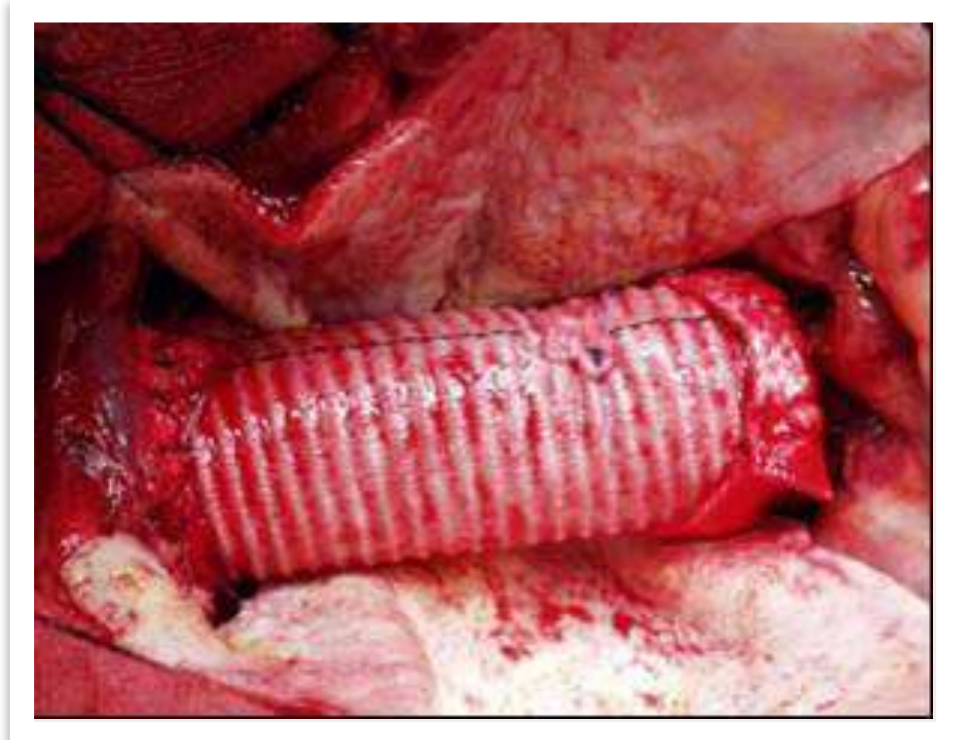

FIGURA 4. Cirurgia profilática visando o reparo da aorta por meio da substituição da região do aneurisma por uma prótese (Fonte: http://my.clevelandclinic.org/).

Até pouco tempo, a descrição da SMF, bem como seus critérios diagnósticos, estavam focados nas avaliações referentes aos três principais órgãos e sistemas envolvidos: o sistema esquelético, os olhos e o coração juntamente com a aorta. Contudo, a pele, a face, os pulmões, os músculos esqueléticos e tecido adiposo, estão claramente envolvidos (Fig.5). Ocasionalmente o envolvimento de qualquer uma desses sistemas pode ser classificado como a principal manifestação clínica de um determinado paciente, assim, para que seja realizado um diagnóstico adequado, faz-se necessário uma avaliação muito criteriosa (PYERITZ, 2000). 

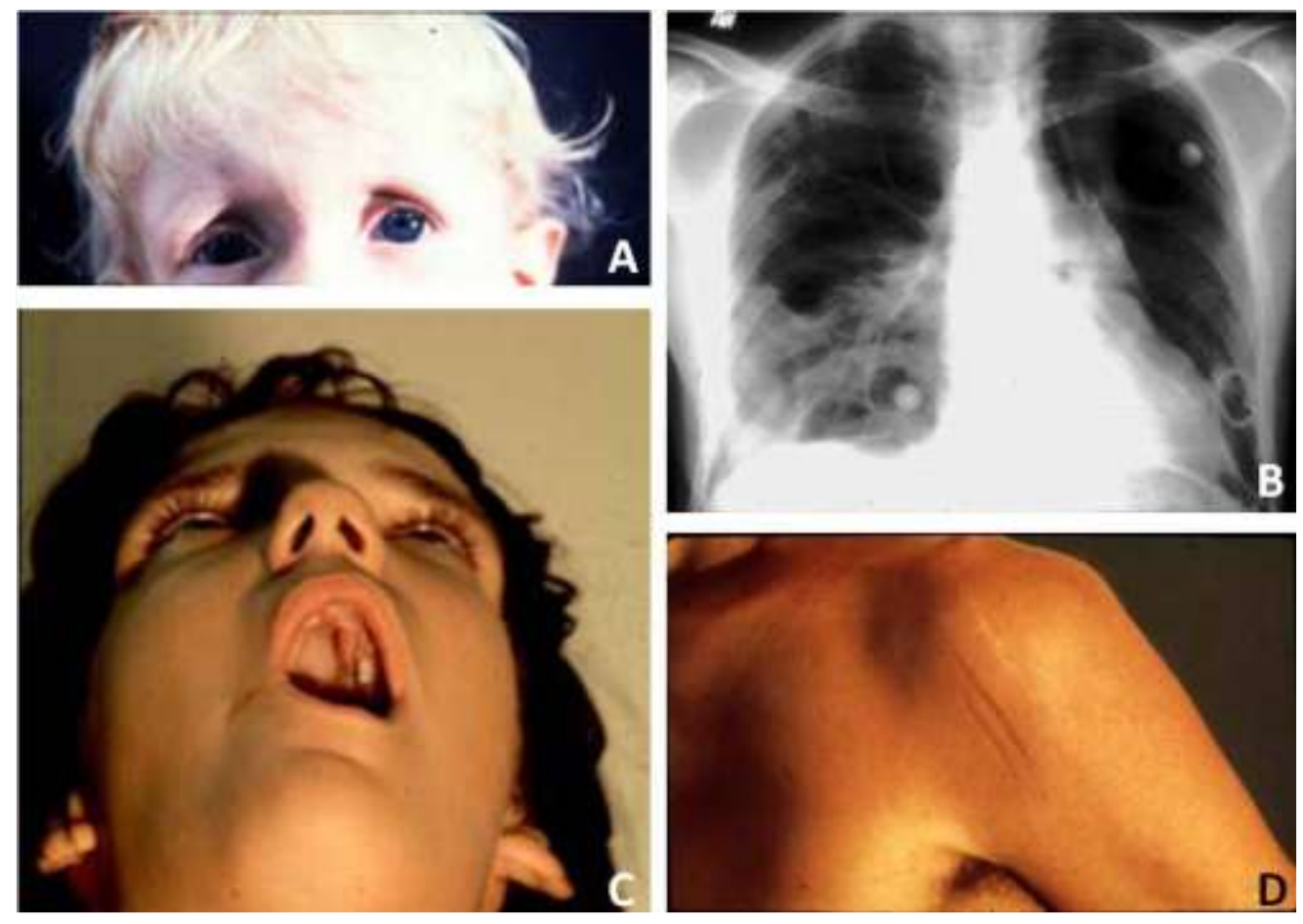

FIGURA 5. Outras características clínicas da SMF. A. Deformidades faciais; B. Enfisema pulmonar; C. Elevação do palato; D. Lesões de pele (Fonte: http://para-leeralgo.blogspot.com/2009/03/sindrome-de-marfan.html).

Dilemas diagnósticos podem ocorrer devido à grande variabilidade clínica inter e intrafamilial da SMF. Além disso, características como prolapso da valva mitral, escoliose, deslocamento do cristalino etc., podem estar presentes em outras doenças do tecido conjuntivo (ROBINSON \& GODFREY, 2000). Assim o diagnóstico da SMF deve seguir as recomendações estabelecidas pelo Comitê Internacional de Nosologia (Ghent nosology) (PYERITZ, 2000). De acordo com essas recomendações, em um caso isolado é necessário que pelo menos dois dos sistemas cardinais na síndrome (ocular, ósseo e cardiovascular) apresentem alterações, como luxação do cristalino, e dilatação ou dissecção da aorta, bem como o envolvimento de um terceiro sistema. Nos casos familiares, o indivíduo deve apresentar a principal manifestação descrita em sua família, associada a uma alteração em dos sistemas cardinais, e o envolvimento de um terceiro sistema. 
A descoberta da relação entre mutações entre o gene FBN1 com 0 desenvolvimento das manifestações fenotípicas da SMF, permitiu uma maior exatidão no diagnóstico de determinados casos (LOEYS et al., 2010). Novas técnicas moleculares permitem a detecção de mutações no gene FBN1 em até 97\% dos pacientes com SMF que preencheram todos os critérios estabelecidos pelo comitê (LOEYS et al., 2001 ; LOEYS et al., 2004).

\subsection{O gene FBN1 e a SMF}

Em 1991, mutações no gene FBN1 (OMIM 134797), que codifica a proteína de matriz extracelular (MEC) fibrilina-1, foram relacionadas à SMF, fazendo com que essa doença fosse classificada no grupo das fibrilinopatias (DIETZ et al., 1991 ; KAINULAINEN \& PELTONEN, 1991). Trata-se de um gene relativamente grande, localizado na região 15q21.1, com aproximadamente 230 kb e composto por 65 exons (PEREIRA et al., 1993). Mais de 500 mutações, distribuídas em quase todos os exons do gene, já foram identificadas e, com exceção de um pequeno grupo de mutações recorrentes, as mutações são únicas, sendo encontradas em famílias isoladas (BOILEAU et al., 2005).

Aproximadamente $25 \%$ de todas as mutações já identificadas no gene FBN1 em pacientes com SMF resultam em inserções ou deleções de bases na seqüência do gene que levam a uma troca no quadro de leitura do mesmo e a um códon de parada de tradução prematuro (BOILEAU et al., 2005). 
Embora ainda não seja possível fazer uma correlação precisa entre genótipo e fenótipo, mutações em determinadas regiões do gene parecem estar relacionadas com a gravidade da doença. Mutações descritas na região entre os exons 24 e 32 foram associadas à forma mais grave da doença, a forma neonatal de SMF (ROBINSON \& GODFREY, 2000). Mutações descritas na região entre os exons 59 e 65 foram associadas à forma intermediária da doença (PALZ et al., 2000). Porém essas associações não possuem valor preditivo da gravidade do fenótipo.

A grande maioria das mutações foi descrita como apresentando penetrância completa (PYERITZ, 1986), embora alguns indivíduos portadores de mutações no gene FBN1 não apresentem qualquer um dos sinais clínicos mais evidentes da SMF. Dentre esses casos raros, nos chama mais atenção um caso familiar, onde dois indivíduos, um filho de 18 anos de idade e sua mãe de 41 anos de idade, eram portadores da mutação (R2726W), embora apenas o filho apresentasse fenótipo (BUONI et al., 2004).

1.4. A Fibrilina-1 e os possíveis mecanismos patogênicos

A fibrilina-1 é a principal componente estrutural das microfibras de 10-12 nm, amplamente distribuídas na MEC de uma grande variedade de tecidos e órgãos, tanto em tecidos elásticos, associados a moléculas de elastina, quanto em tecidos não elásticos (RAMIREZ \& PEREIRA, 1999). A proteína foi primeiramente isolada em 1986, a partir de culturas de fibroblastos, utilizando-se anticorpos monoclonais contra âmnio humano digerido por pepsina (SAKAI et al., 1986). Em 1993, Pereira et 
al. concluíram definitivamente a estrutura primária da pré-fibrilina, a molécula precursora da fibrilina-1, caracterizando-a como um peptídeo composto por 2871 aminoácidos e com um peso molecular estimado de 347 kDa.

A fibrilina-1 é uma glicoproteína cujas moléculas apresentam em sua estrutura diversas repetições homólogas, ricas em cisteínas, de forma semelhante à encontrada em outras proteínas, como as fibulinas-1 e 2 e a proteína de ligação ao TGF-ß1 (LTBP). Essas repetições são classificadas como unidades calcium-binding EGF-precursor-like ( $c b E G F)$, por serem semelhantes aos já descritos módulos EGF (epidermal growth factor), e apresentam algumas funções críticas, como proteção contra as ações proteolíticas extracelulares, mediação da interação entre monômeros, favorecimento do empacotamento lateral de microfibras, organização de macroagregados, entre outras (KIELTY \& SHUTTLEWORTH, 1995). A fibrilina-1 é composta basicamente de quarenta e sete módulos EGF, sendo que quarenta e três destes módulos associados ao cálcio ( $c b E G F$ ), sete módulos TB (módulos com oito cisteínas, primeiramente descritos na LTBP) e três módulos Fib, módulos híbridos que possuem características tanto dos domínios EGF quanto dos domínios TB (Fig.8) (PEREIRA et al., 1993). 


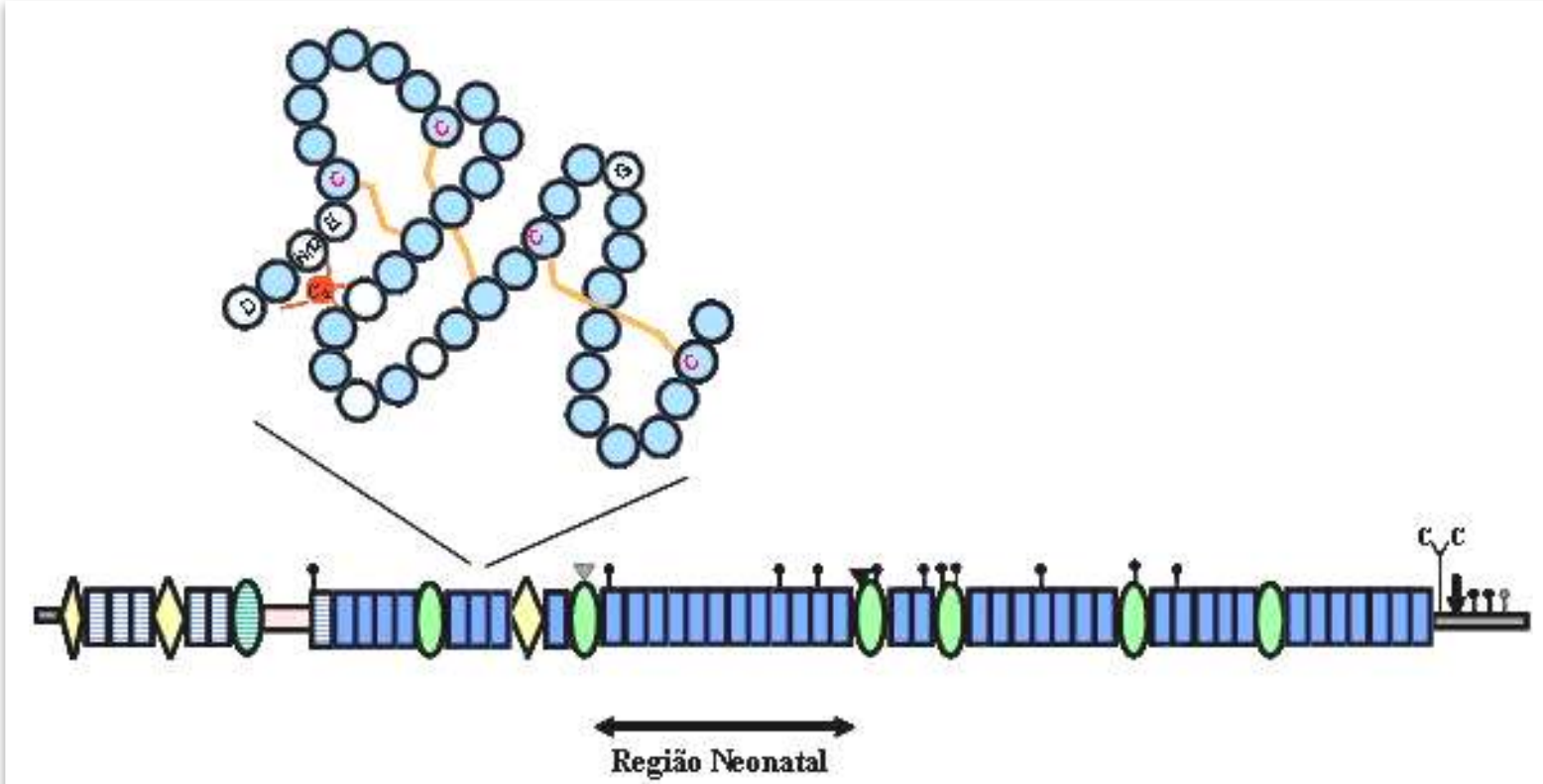

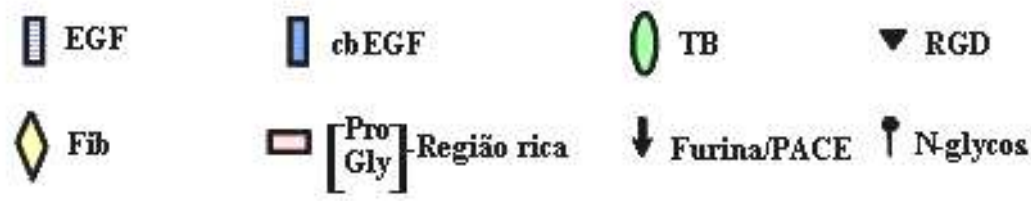

FIGURA 8. Estrutura primária da fibrilina-1. EGF (epidermal growth factor); TB (LTBP - latent transforming growth factor- $\beta$ binding protein); $\mathrm{CbEGF}$ (calcium binding epidermal growth factor) ; Fib (hibridos de EGF e TB); N-glycos (sítio de glicosilação); furina/PACE (sítio de endoprotease); RGD (seqüência Arg-Gly-Asp) (SANTOS, 2005).

A maior parte da síntese de fibrilina-1 parece estar associada a processos tardios de morfogênese. Estudos sugerem que as fibrilinas estão relacionadas ao processo de eslatogênese, pois as microfibras estão presentes na MEC antes da deposição de tropoelastinas. Por esse motivo, uma deficiência na síntese ou na estrutura da fibrilina-1 poderia prejudicar a formação de fibras elásticas, levando a processos patológicos como a dissecção da aorta (ZHANG et al., 1995).

As microfibras podem desempenhar diversas funções, em diferentes tecidos. Em tecidos não elásticos, elas apresentam a função de ancoragem, como por exemplo, a ligação entre as lentes e o corpo ciliar dos olhos. Em tecidos elásticos, elas promovem a adesão entre as fibras elásticas, e dessas as outras estruturas e a 
componentes celulares. A relação funcional entre a fibrilina-1 e o esqueleto pode estar ligada às forças de tensão que regulam o crescimento ósseo. Microfibras ricas em fibrilina-1, presentes no periósteo, podem controlar negativamente o crescimento dos mesmos, pela manutenção de tensões periósteas, e pela força de tensionamento dos ligamentos e tendões (ZHANG et al., 1995).

Durante a sua secreção celular as moléculas de profibrilina-1 são processadas e agregadas à MEC junto com outras proteínas, formando assim as microfibras (KIELTY et al., 2002). Esse processo ainda não está completamente compreendido, e por isso o mecanismo patogênico da SMF permanece desconhecido. Contudo, por tratar-se de uma proteína multimérica, uma hipótese sugere que os monômeros de fibrilina-1 mutados poderiam exercer um efeito dominante negativo sobre os monômeros normais em pacientes heterozigotos (DIETZ et al., 1993a). Pacientes com um menor nível de expressão de proteína mutada parecem apresentar um quadro clínico da SMF mais leve, corroborando com este modelo dominante negativo (DIETZ et al., 1993b).

Uma segunda hipótese sugere que um mecanismo de haploinsuficiência possa estar associado com a doença. Em estudos realizados com modelos animais, assim como em pacientes com SMF, o nível de expressão da proteína normal mostrou estar relacionado com a gravidade do quadro clínico da doença (HUTCHINSON et al., 2003 ; JUDGE et al., 2004). Em um estudo foi descrito um indivíduo com alterações esqueléticas que possuía a mutação R2726W no gene FBN1 (MILEWICZ et al., 1995). Essa mutação gera uma alteração na região Cterminal da proteína fibrilina-1, impedindo que os monômeros mutantes possam se agregar às microfibras - na prática o equivalente a um alelo nulo do FBN1. Isso 
sugere que esse indivíduo deve apresentar um fenótipo associado a um modelo de haploinsuficiência.

Uma vez que os níveis de expressão da fibrilina-1 normal parecem apresentar o potencial de modular os efeitos patogênicos das proteínas mutadas, é possível que uma variação no nível de expressão dos alelos normais do gene FBN1 possa explicar parte da heterogeneidade clínica encontrada em pacientes com SMF (HUTCHINSON et al., 2003).

1.5. O efeito das mutações do gene FBN1 sobre a citosina TGF- $\beta 1$

Algumas das características da SMF, como alterações no crescimento dos músculos esqueléticos e no metabolismo de gorduras, e o desenvolvimento de enfisema pulmonar, não parecem estar relacionadas com falhas na função estrutural desempenhada pela fibrilina-1 (BYERS, 2004). Essas alterações parecem estar mais relacionadas com perturbações de desenvolvimento, do que com falhas simplesmente mecânicas (NEPTUNE et al., 2003).

Após a sua síntese e processamento, as moléculas de fibrilina-1 passam a compor a matriz extracelular, associando-se a outras proteínas, como a LTBP-1 (BYERS, 2004). As LTBPs são muito importantes por propiciarem um sítio de ligação para as moléculas latentes de TGF- $\beta 1$ (transforming growth factor $\beta 1$ ), até que essas sejam liberadas e ativadas, devido a perturbações nos elementos constituintes da MEC (ANNES et al., 2003). Elas são membros da família de proteínas LTBP/fibrilina, 
a qual compreende a fibrilina-1, fibrilina-2 e fibrilina-3, e as LTBP-1, LTBP-2, LTPB-3 e LTBP-4 (NAKAJIMA et al., 1999 ; BYERS, 2004). A similaridade da seqüência e da estrutura entre as LTBPs e as fibrilinas (Fig.9A) sugeriu que a fibrilina-1 também poderia prover um sítio de ligação para moléculas latentes de TGF- $\beta 1$ (NAKAJIMA et al., 1999). Contudo, a fibrilina-1 não parece ligar-se diretamente a essa proteína (SAHARINEN \& KESKI-OJA, 2000). Por outro lado, a porção N-terminal da fibrilina-1 está ligada à porção C-terminal da LTPB-1 (Fig.9B), permitindo que alterações na MEC levem à liberação de moléculas latentes de TGF- $\beta 1$, passando para sua forma ativa (KAARTINEN \& WARBURTON, 2003).

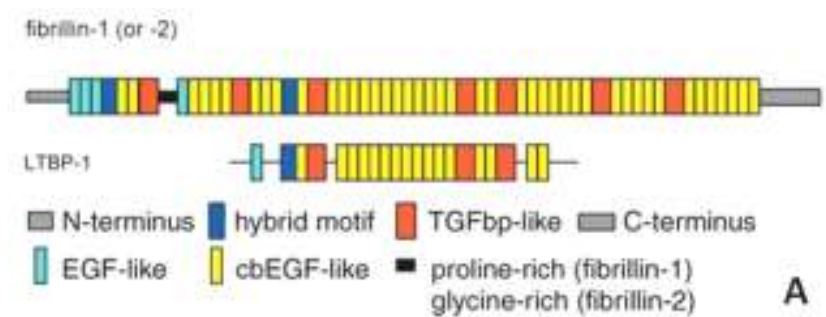

FGURA 9. A relação entre a fibrilina-1 e a LTBP-1. A. A Similaridade entre as duas proteínas (NEPTUNE et al., 2003); B. A ligação da porção N-terminal da fibrilina à porção C-terminal da LTPB-1 (BYERS, 2004).

O TGF- $\beta 1$ é uma importante citosina moduladora de crescimento celular, processos inflamatórios, síntese da MEC, ativação de proteinases e apoptose (TAIPALE et al., 1998). Mudanças no padrão de atividade de TGF-ß1 estão associadas com várias alterações, como crescimento de células tumorais, fibroses e doenças autoimunes (BLOBE et al., 2000). Este padrão de atividade é 
primariamente definido pela conversão das moléculas latentes de TGF- $\beta 1$ para sua forma ativa (ANNES et al., 2003).

A hipótese de que a fibrilina-1 é mais do que apenas uma proteína estrutural, e que poderia estar participando no controle da sinalização de TGF- $\beta 1$ foi testada em camundongos com mutações do tipo knockdown no gene Fbn1 (NEPTUNE et al., 2003). Estes animais apresentam níveis aumentados de TGF- $\beta 1$ ativo nos seus pulmões, assim como um aumento do espaço alveolar, e desenvolvimento de enfisema durante o seu envelhecimento. Essa alteração foi revertida a partir do tratamento desses animais com anticorpos para TGF- $\beta 1$, ainda em fase uterina.

1.6. As proteínas associadas à via de sinalização de TGF- $\beta 1$

As proteínas Smad são componentes essenciais das vias de sinalização intracelular dependentes de TGF- $\beta 1$, e participam da formação de fibroses induzidas por TGF-ß1 (Fig.10) (MASSAGUE \& CHEN, 2000). Após sua ativação, a citosina TGF- $\beta 1$ transmite seu sinal através da membrana plasmática, ancorando-se a 2 receptores serina/treonina kinases específicos, dos tipos I e II. Ao ancorar-se ao receptor tipo II, o qual ativa o receptor tipo I, faz com que este último fosforile duas receptor-regulated Smads (R-Smads), Smad2 e Smad3. Ambas acabam por se dissociar do complexo receptor, para formar um novo complexo heterotrimérico com a Smad4. Por fim esses complexos são translocados para o núcleo, atuando como reguladores transcricionais de genes alvos (MASSAGUE \& CHEN, 2000 ; JAVELAUD \& MAUVIEL, 2004). Assim, a quantificação da proteína Smad2 
fosforilada é um bom método para a determinação do nível de atividade da citosina TGF- $\beta 1$ em tecidos.

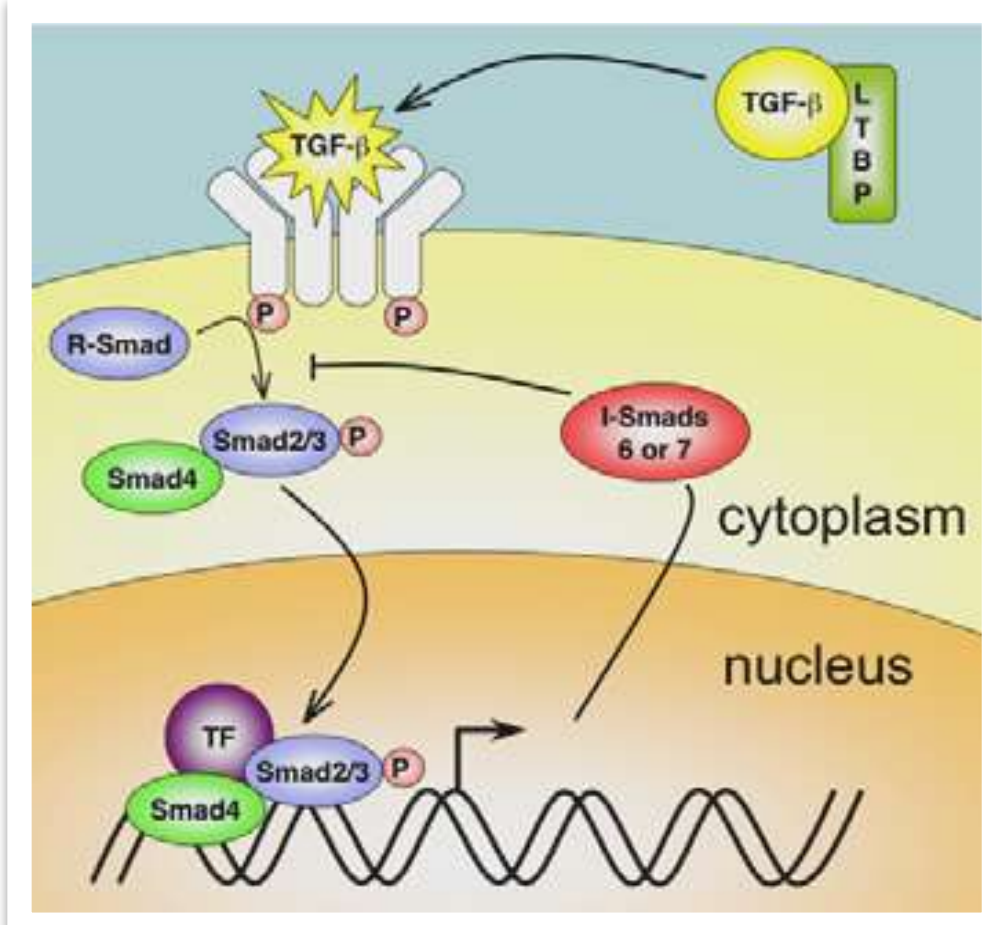

FIGURA 10. Representação esquemática para a via de sinalização da citosina TGF- $\beta 1$ (COHN et al., 2007).

A proteína Angiotensina II (Ang II) é uma reguladora de crescimento celular, processos inflamatórios e fibrose, contribuindo para o surgimento de danos vasculares. Em diferentes doenças e processos celulares, Ang II tem o papel regulatório sobre a expressão de TGF- $\beta 1$, o qual pode mediar algumas respostas à Ang II. Drogas inibidoras da ACE (Angiotensin-converting enzyme) e antagonistas de AT1 (receptor tipo I para angiotensina-II) diminuem a expressão de TGF- $\beta 1$ e formação de fibroses, assim como o bloqueio de TGF- $\beta 1$ diminui a produção de Ang II na matriz extracelular (BORDER \& NOBLE, 1998 ; RUIZ-ORTEGA et al., 2003 ; RODRIGUEZ-VITA et al., 2005). 
Baseados nesta nova função da fibrilina-1, de moduladora dos níveis de TGF- $\beta 1$ ativo na matriz, novas estratégias terapêuticas para a SMF foram testadas. A administração de uma droga antagonista de AT1, Losartan, em um modelo murino para SMF foi capaz de diminuir a atividade de TGF- $\beta 1$, resultando em reversão dos fenótipos pulmonares e aórticos desses animais (HABASHI et al., 2006). Atualmente um tratamento similar em seres humanos está em teste clínico em vários países (DETAINT et al., 2010 ; RADONIC et al., 2010).

1.7. A utilização de fármacos no tratamento da síndrome de Marfan

Devido aos problemas vasculares agudos presentes em pacientes portadores da SMF, como principalmente o rompimento da artéria aorta, um dos tratamentos mais utilizados para a síndrome baseia-se na administração de drogas anti-hipertensivas. Em geral tais drogas reduzem a rigidez das paredes arteriais por ação passiva, diminuindo a pressão arterial. Pesquisas recentes vêm demonstrando que algumas das drogas mais utilizadas, em particular as inibidoras da $A C E$ e as antagonistas de AT1, podem ter um efeito adicional sobre a constituição da parede arterial, o que pode contribuir na redução da sua rigidez (AHIMASTOS et al., 2005). Dentre essas drogas, encontramos o Losartan, descrito anteriormente, e o Ramipril.

Ahimastos et al. (2005) descreveram que a droga Ramipril parece ter grande influência na estrutura das paredes arteriais. Nesse estudo os pesquisadores demonstraram que células humanas de músculo liso tratadas em cultura com Ramipril apresentam um decréscimo na deposição de colágeno da ordem de $50 \%$, assim como um aumento na deposição de elastina e fibrilina-1 da ordem de três 
vezes e quatro vezes, respectivamente. Além disso, a droga leva a uma redução da transcrição dos genes MMP-2 e MMP-3, que codificam as metaloproteinases 2 e 3, envolvidas na degradação de proteínas da MEC (BOOMS et al., 2000).

1.8. Os modelos murinos para a síndrome de Marfan

Um dos temas de estudos emergentes é o desenvolvimento de camundongos mutantes para o estudo de doenças genéticas. Os camundongos (Mus musculus) mostram-se uma espécie com grandes vantagens para a realização de pesquisas científicas. São animais de fácil armazenamento e manipulação, com uma elevada taxa de reprodução, atingem idade reprodutiva rapidamente e possuem um período curto de gestação. Além disso, atualmente já se encontra disponível, em bancos de dados públicos, a seqüência genômica da espécie, e existem diversas técnicas bem estabelecidas de manipulação do genoma desses animais.

No caso da SMF, três modelos animais foram criados visando o estudo (1) da doença nos diferentes sistemas afetados; (2) e da função da proteína fibrilina-1 durante o desenvolvimento embrionário e a vida pós-natal (PEREIRA et al., 1999).

O primeiro modelo, a linhagem $\mathrm{mg} \Delta$, possui uma deleção em fase dos exons 19 a 25 do gene Fbn1 (Fig.12), substituídos por um cassete de expressão do gene de resistência à neomicina (neoR) (PEREIRA et al., 1997). Surpreendentemente, os animais heterozigotos não apresentam nenhum fenótipo, enquanto que os homozigotos morrem com até duas semanas de vida pós-natal por falhas no sistema 
cardiovascular. A análise detalhada do alelo $F b n 1^{\mathrm{mg} \Delta}$ revelou que este produz somente $10 \%$ dos níveis de mRNA produzidos pelo alelo normal, sugerindo que de fato o fenótipo da SMF seja decorrente da presença de quantidades significativas de fibrilinas mutantes, de acordo com o modelo dominante-negativo. A baixa quantidade de moléculas de fibrilinas mutantes naqueles animais não seria suficiente para causar a desorganização das microfibras.

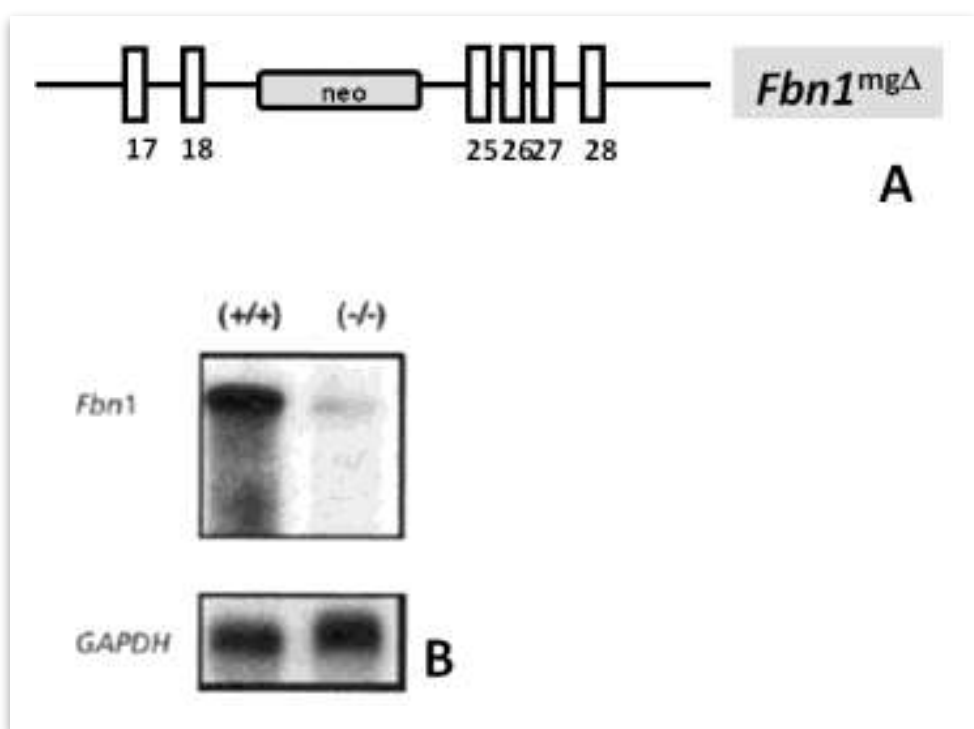

FIGURA 12. O modelo $\mathrm{mg} \Delta$. A. Representação esquemática do alelo $F b n 1^{\mathrm{mg} \Delta}$. Os retângulos vazios representam os exons do gene Fbn1 e o retângulo cinza o cassete NeoR; B. Análise por Northernblot desmontando que o alelo $F b n 1^{\mathrm{mg} \Delta}$ (direita) produz somente $10 \%$ dos níveis de mRNA produzidos pelo alelo normal (PEREIRA et al., 1997).

A linhagem mgR é resultado de uma recombinação aberrante entre o vetor de recombinação homóloga e a seqüência alvo do gene Fbn1 (Fig.13) (PEREIRA et al., 1999). De maneira similar ao alelo $F b n 1^{\mathrm{mg} \Delta}$, o alelo $F b n 1^{\mathrm{mgR}}$ apresenta o cassete neoR inserido no intron 18, no entanto a seqüência endógena, correspondente aos exons 19 a 25, não foi deletada, e assim o alelo $F b n 1^{\mathrm{mgR}}$ produz fibrilina-1 normal. Como os animais $\mathrm{mg} \Delta$, os $\mathrm{mgR}$ heterozigotos não possuem nenhum fenótipo. Já os as animais $\mathrm{mgR}$ homozigotos apresentam uma longevidade superior aos da linhagem $\mathrm{mg} \Delta$, embora também apresentem alterações vasculares. A análise do 
alelo $F b n 1^{\mathrm{mgR}}$ revelou que este produz $20 \%$ dos níveis de mRNA do alelo normal, e assim o fenótipo dos mgR homozigotos é devido à diminuição dos níveis de fibrilina1 normal (PEREIRA et al., 1999).

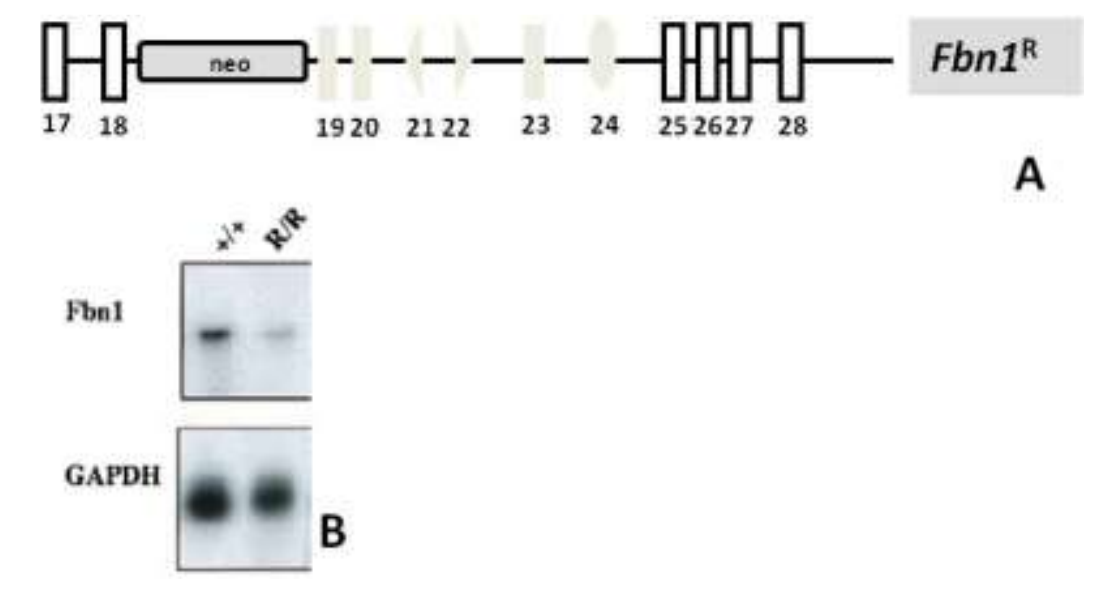

FIGURA 13. O modelo mgR. A. Representação esquemática do alelo $F b n 1^{\mathrm{mgR}}$. Os retângulos brancos representam os exons do gene Fbn1, as formas cinza representam os exons deletados na linhagem $\mathrm{mg} \Delta$, e o retângulo cinza grande representa o cassete neoR; B. Análise por Northern-blot demonstrando que o alelo $F b n 1^{\mathrm{mgR}}$ (direita) produz somente $20 \%$ dos níveis de mRNA produzidos pelo alelo normal (PEREIRA et al., 1999).

Nesses modelos foram identificados entre outros: o papel da fibrilina-1 no suporte estrutural da fibra elástica na vida pós-natal e não na formação desta durante o desenvolvimento embrionário (PEREIRA et al., 1997); a contribuição da resposta inflamatória na progressão das lesões vasculares (PEREIRA et al., 1999); o papel da fibrilina-1 no controle da ativação de TGF- $\beta 1$ no pulmão, e a contribuição desta citosina nas manifestações da SMF (NEPTUNE et al., 2003).

Apesar de serem instrumentos de pesquisa importantes, esses dois modelos animais apresentaram o fenótipo somente em homozigose. Aparentemente, a presença do cassete neoR no intron 18 leva à baixa expressão dos alelos mutantes $F b n 1^{\mathrm{mg} \Delta}$ e $F b n 1^{\mathrm{mgR}}$, impedindo a manifestação do efeito dominante-negativo característico da SMF (PEREIRA et al., 1997 ; PEREIRA et al., 1999). Assim, para a geração de um modelo animal para a SMF, seria necessário utilizar o sistema de 
recombinação CRE-loxP (SUNAGA et al., 1997) para eliminar o cassete de expressão neoR e assim obter um alelo mutante Fbn1 com nível de expressão equivalente ao do alelo selvagem.

O terceiro modelo animal para a SMF, a linhagem de camundongos C1039G, é caracterizado pela substituição de uma cisteína por uma glicina na posição 1039, em um domínio EGF da fibrilina-1, sendo este o tipo mais comum de mutação em FBN1 em indivíduos com SMF. Animais heterozigotos apresentam deficiência na deposição de microfibrilas na MEC, alterações esqueléticas e progressiva deterioração da arquitetura da parede aórtica (Fig.14) (JUDGE et al., 2004).

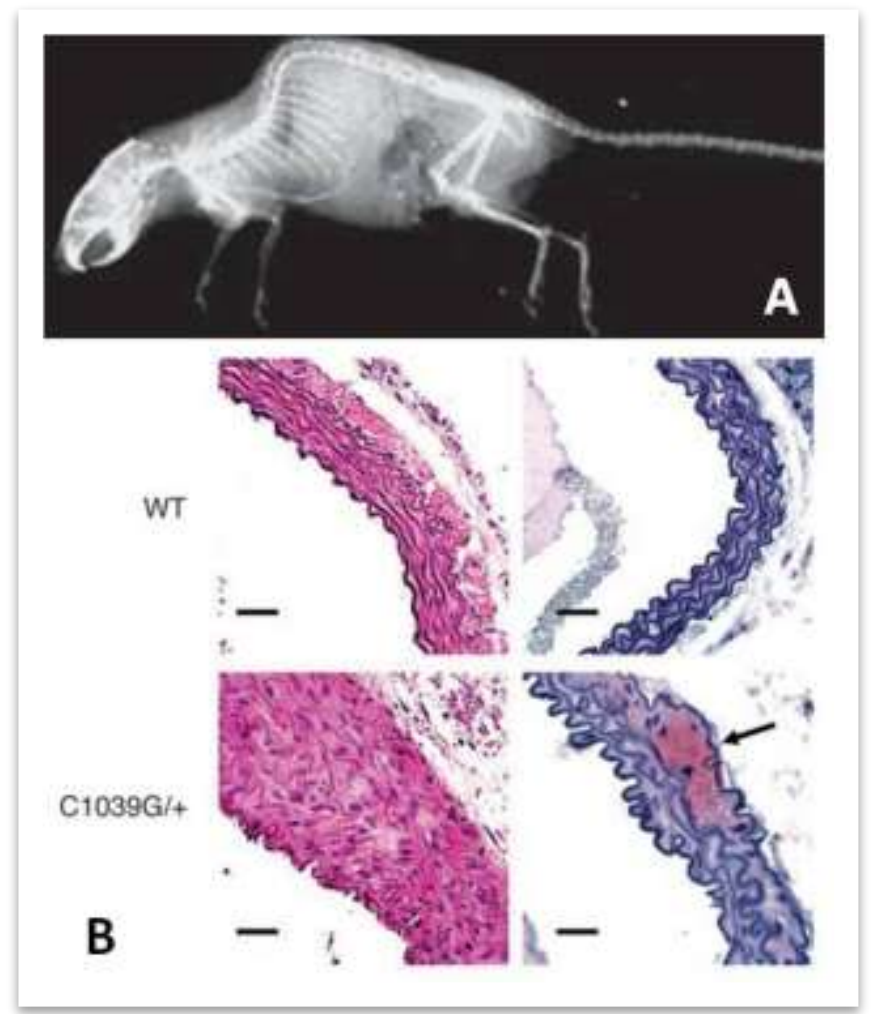

FIGURA 14. O modelo C1039G. A. Imagem radiográfica de um animal heterozigoto C1039G; B. Comparação histológica da parede aórtica de um animal selvagem (WT) e um animal heterozigoto C1039G. À esquerda coloração HE e à direita coloração de Weigert, específica para a visualização de fibras elásticas. A flecha indica um ponto de calcificação (JUDGE et al., 2004). 
Além dos modelos desenvolvidos em laboratório, temos ainda o modelo Tight Skin (Tsk), um mutante natural, que por possuir uma mutação no gene Fbn1, apresenta algumas características da SMF, incluindo o crescimento exagerado dos ossos longos e enfisema pulmonar. A mutação desses animais caracteriza-se pela duplicação da região dos exons 19 a 24. Tal alteração resulta na produção de uma da fibrilina-1 mutada contendo 984 aminoácidos a mais, gerando uma glicoproteína de $418 \mathrm{kDa}$. O animal Tsk heterozigoto apresenta um aumento na produção de tecido ósseo, enfisema pulmonar e um aumento do tecido conjuntivo (Fig.15). Diferente dos modelos anteriores, este animal não apresenta complicações cardiovasculares características da SMF. Quando em homozigose, o modelo Tsk morre ainda no estágio embrionário de pré-implantação (GAYRAUD et al., 2000).

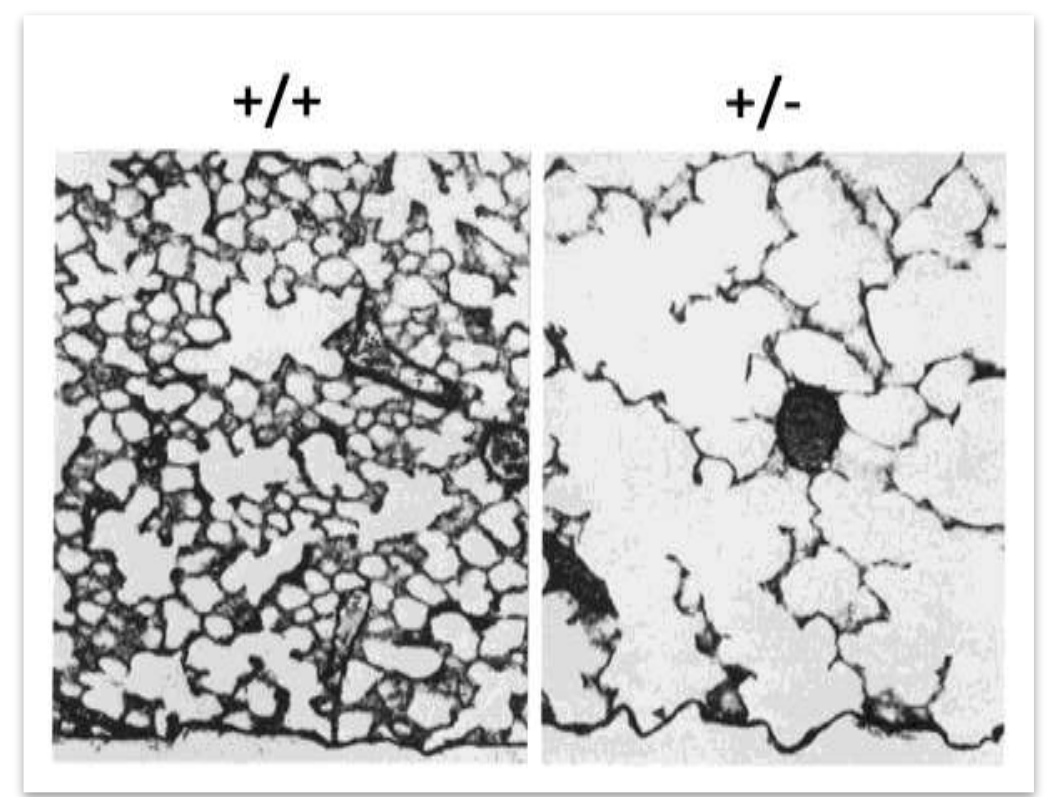

FIGURA 15. O modelo Tight Skin. Comparação de cortes histológicos de pulmão de um animal selvagem e um animal mutante, indicando a presença de enfisema em animais Tsk (GREEN et al., 1976). 


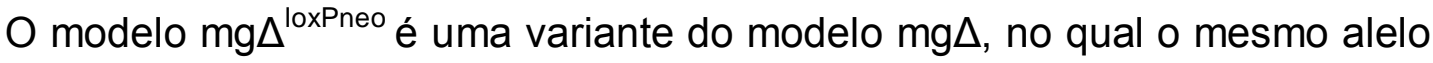
mutante está presente, porém com o cassete neoR flanqueado por duas seqüência lox-P (Fig.16), permitindo a deleção do cassete de resistência através da proteína CRE-recombinase (SANTOS, 2005). O objetivo da criação deste alelo do gene Fbn1 foi o desenvolvimento de um modelo onde fosse possível controlar a expressão do alelo mutante, quando esses animais são cruzados com animais transgênicos para a proteína CRE-recombinase.

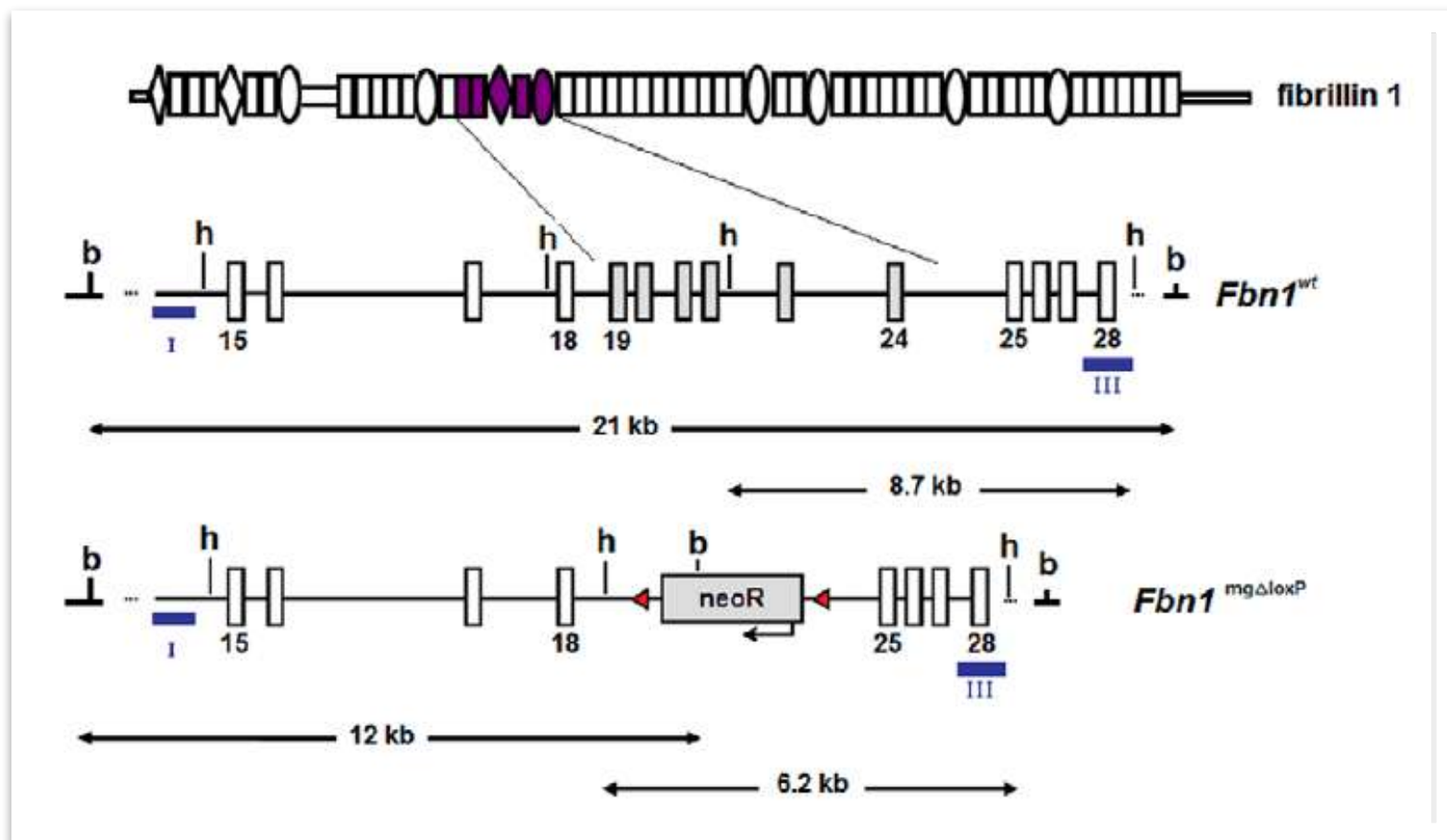

FIGURA 16. Representação esquemática do alelo $F b n 1^{\text {mg } \Delta l o x P n e o}$. Os triângulos vermelhos representam a seqüência loxP flanqueando o gene neoR. Os retângulos vazios representam os exons do gene Fbn1 e os retângulos cinza representam os exons $19-24$ deletados no alelo mg $\Delta^{\text {loxpneo }}$. As barras azuis representam as sondas de DNA utilizadas para identificação da mutação por Southern-blot.

Como observado no modelo $\mathrm{mg} \Delta$ original, os animais $\mathrm{mg} \Delta^{\text {loxPneo }}$ heterozigotos da primeira geração $(F 1)$ não apresentavam nenhum fenótipo. Contudo, em cruzamentos subseqüentes, foram obtidos alguns animais, também heterozigotos, com um fenótipo muito grave da SMF, caracterizado por 
deformidades na coluna vertebral e alterações pulmonares (enfisema) (Fig.17). De um total de 47 animais heterozigotos, quatro apresentaram as características mencionadas, e morreram aos três meses de idade por causas desconhecidas, porém a presença de hemotórax sugeriu ruptura da aorta (SANTOS, 2005).

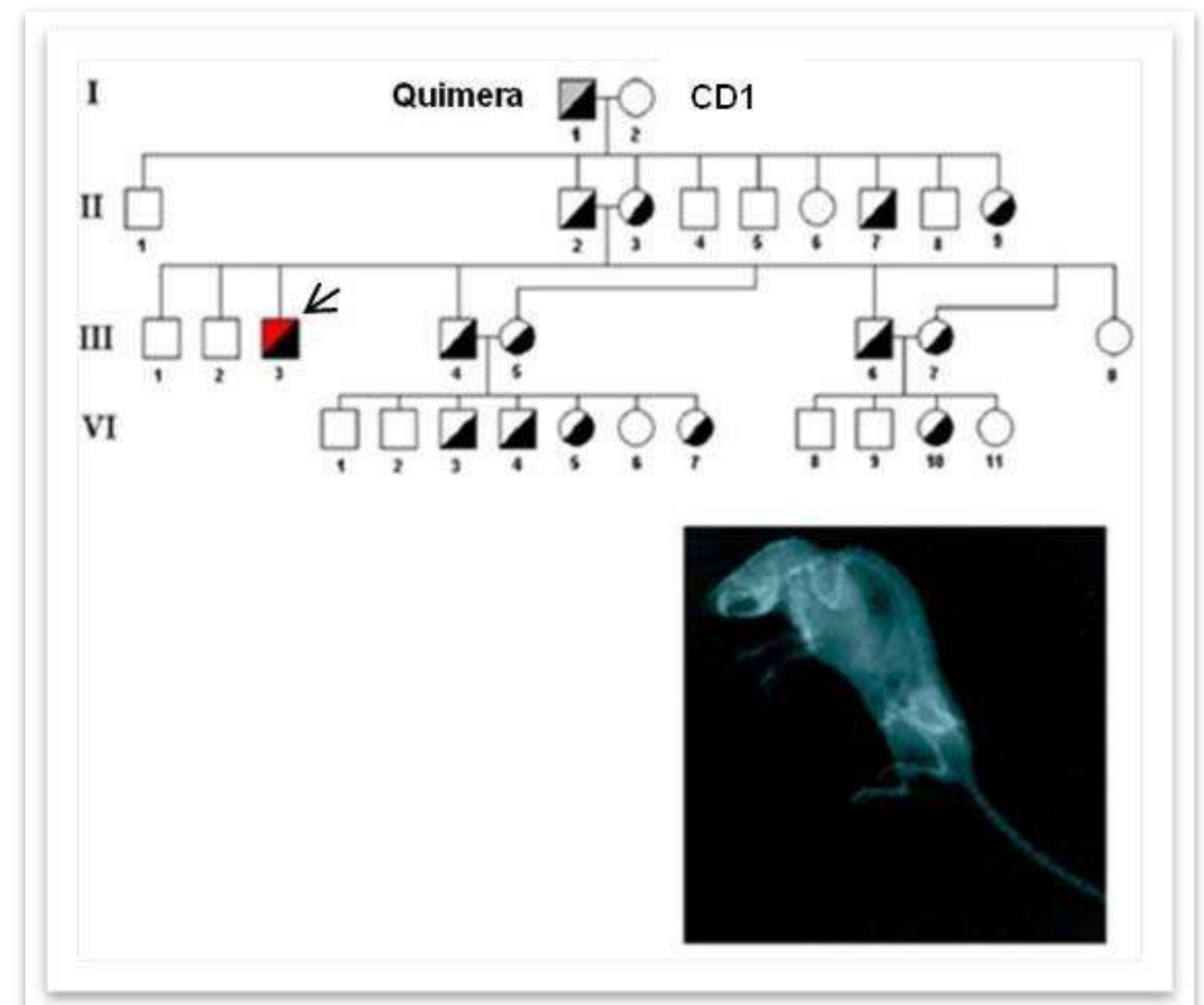

FIGURA 17. Heredograma dos camundongos heterozigotos fundadores da linhagem $\mathrm{mg} \Delta^{\text {loxpneo }}$. Os animais híbridos (129/Sv / CD1) eram assintomáticos até que em F3 um animal gravemente afetado foi encontrado (flecha). A radiografia desse animal encontra-se na figura (SANTOS, 2005).

Todos estes animais eram derivados de cruzamentos entre duas linhagens murinas diferentes, a linhagem outbred CD-1 e a linhagem isogênica 129/Sv. Esse fato foi sugestivo de que a variabilidade fenotípica observada poderia estar relacionada com diferenças no background genético dos animais. Para testar essa hipótese, o alelo $F b n 1^{\text {mgdloxPneo }}$ foi colocado em duas linhagens isogênicas, a linhagem C57BL/6 e a 129/Sv (SANTOS, 2005). 
Os animais heterozigotos da linhagem C57BL/6 mostraram-se assintomáticos, enquanto que os animais heterozigotos da linhagem 129/Sv podiam apresentar desde um fenótipo leve até um fenótipo muito grave, reproduzindo a variabilidade fenotípica interfamilial observada na SMF. Assim o modelo $\mathrm{mg} \Delta^{\text {loxPneo }}$ mostrou-se adequado não só para o estudo dos mecanismos de patogênese relacionados à SMF, como potencialmente para o estudo da variabilidade clínica da síndrome (SANTOS, 2005). 
1. Caracterizamos a presença de variabilidade fenotípica no modelo animal mg $\Delta^{\text {loxPneo }}$ para SMF, em animais mutantes das linhagens murinas $129 / \mathrm{Sv}$ e B6, estabelecendo assim um sistema experimental para a identificação de genes modificadores do fenótipo da doença;

2. Caracterizamos a variabilidade fenotípica do modelo $\mathrm{mg} \Delta^{\text {loxPneo }}$ dentro da linhagem congênica 129/Sv, cujo fenótipo variou de assintomático a grave. Propomos então que fatores epigenéticos modulam a gravidade do fenótipo nesses animais;

3. Observamos em animais heterozigotos da linhagem 129/Sv a existência de uma forte correlação negativa entre a variabilidade fenotípica e variabilidade transcricional global do gene Fbn1. Assim, podemos inferir que a quantidade de proteína fibrilina-1 pode modular a gravidade da doença. Outro dado que sustenta essa hipótese é o fato dos animais B6, os quais não mostram variabilidade fenotípica, também serem bastante homogêneos no que se refere à transcrição do gene Fbn1;

4. Verificamos uma diminuição gradativa na quantidade de fibrilina-1 produzida pelo organismo durante o seu envelhecimento. Essa diminuição pode estar relacionada com a característica progressiva da doença. Em indivíduos heterozigotos a taxa de degradação da proteína pode estar superando a capacidade de reposição da mesma;

5. Sendo a quantidade de proteína um fator importante para a determinação da gravidade dos fenótipos, bem como para sua progressão, propomos que novas estratégias terapêuticas para a SMF sejam baseadas no aumento da síntese de fibrilina-1; 
6. O tratamento de animais mutantes com a droga Ramipril, com uma dosagem equivalente a já utilizada em humanos, resultou em um aumento de aproximadamente $35 \%$ da transcrição global dom gene $F b n 1$, quando comparado com animais mutantes não tratados. Além disso, os animais tratados apresentaram melhora fenotípica nos sistemas ósseo e pulmonar, tendo atingido níveis normais no primeiro. Esses resultados reforçam a hipótese da importante relação entre a quantidade de fibrilina-1 com a variação de fenótipo, e indicam outros fatores modulam o fenótipo nos diferentes sistemas. 
VII. REFERÊNCIAS 
ADACHI, Y., H. OYAIZU, et al. Treatment and transfer of emphysema by a new bone marrow transplantation method from normal mice to Tsk mice and vice versa. Stem Cells, v.24, n.9, Sep, p.2071-7. 2006.

ADES, L. Guidelines for the diagnosis and management of Marfan syndrome. Heart Lung Circ, v.16, n.1, Feb, p.28-30. 2007.

AHIMASTOS, A. A., A. K. NATOLI, et al. Ramipril reduces large-artery stiffness in peripheral arterial disease and promotes elastogenic remodeling in cell culture. Hypertension, v.45, n.6, Jun, p.1194-9. 2005.

ALDRED, C. e A. T. SANDISON. The Pharaoh Akhenaten. A problem in Egyptology and pathology. Bull Hist Med, v.36, Jul-Aug, p.293-316. 1962.

ANDRIKOPOULOS, K., X. LIU, et al. Targeted mutation in the col5a2 gene reveals a regulatory role for type $\mathrm{V}$ collagen during matrix assembly. Nat Genet, v.9, n.1, Jan, p.31-6. 1995.

ANNES, J. P., J. S. MUNGER, et al. Making sense of latent TGFbeta activation. J Cell Sci, v.116, n.Pt 2, Jan 15, p.217-24. 2003.

AOYAMA, T., U. FRANCKE, et al. Quantitative differences in biosynthesis and extracellular deposition of fibrillin in cultured fibroblasts distinguish five groups of Marfan syndrome patients and suggest distinct pathogenetic mechanisms. $J$ Clin Invest, v.94, n.1, Jul, p.130-7. 1994.

BAYLES, J. Sounding the alarm. If undetected, Marfan syndrome can be a silent killer. J Ark Med Soc, v.99, n.4, Oct, p.106-11. 2002.

BLOBE, G. C., W. P. SCHIEMANN, et al. Role of transforming growth factor beta in human disease. N Engl J Med, v.342, n.18, May 4, p.1350-8. 2000.

BOILEAU, C., G. JONDEAU, et al. Molecular genetics of Marfan syndrome. Curr Opin Cardiol, v.20, n.3, May, p.194-200. 2005.

BOOMS, P., F. TIECKE, et al. Differential effect of FBN1 mutations on in vitro proteolysis of recombinant fibrillin-1 fragments. Hum Genet, v.107, n.3, Sep, p.216-24. 2000.

BORDER, W. A. e N. A. NOBLE. Interactions of transforming growth factor-beta and angiotensin II in renal fibrosis. Hypertension, v.31, n.1 Pt 2, Jan, p.181-8. 1998.

BUONI, S., R. ZANNOLLI, et al. The FBN1 (R2726W) mutation is not fully penetrant. Ann Hum Genet, v.68, n.Pt 6, Nov, p.633-8. 2004.

BYERS, P. H. Determination of the molecular basis of Marfan syndrome: a growth industry. J Clin Invest, v.114, n.2, Jul, p.161-3. 2004.

CHEN, R. H., Y. H. SU, et al. Suppression of transforming growth factor-beta-induced apoptosis through a phosphatidylinositol 3-kinase/Akt-dependent pathway. Oncogene, v.17, n.15, Oct 15, p.1959-68. 1998.

COHN, R. D., C. VAN ERP, et al. Angiotensin II type 1 receptor blockade attenuates TGF-beta-induced failure of muscle regeneration in multiple myopathic states. Nat Med, v.13, n.2, Feb, p.204-10. 2007. 
CONNEELY, K. N., J. W. SCHROEDER, et al. Global and Gene-Specific Changes in DNA Methylation Associated with Aging. 2010 ASHG Annual Meeting Washington, DC, 2010. p.

DETAINT, D., P. AEGERTER, et al. Rationale and design of a randomized clinical trial (Marfan Sartan) of angiotensin II receptor blocker therapy versus placebo in individuals with Marfan syndrome. Arch Cardiovasc Dis, v.103, n.5, May, p.317-25. 2010.

DIETRICH, W. F., E. S. LANDER, et al. Genetic identification of Mom-1, a major modifier locus affecting Min-induced intestinal neoplasia in the mouse. Cell, v.75, n.4, Nov 19, p.631-9. 1993.

DIETZ, H. C., G. R. CUTTING, et al. Marfan syndrome caused by a recurrent de novo missense mutation in the fibrillin gene. Nature, v.352, n.6333, Jul 25, p.337-9. 1991.

DIETZ, H. C., I. MCINTOSH, et al. Four novel FBN1 mutations: significance for mutant transcript level and EGF-like domain calcium binding in the pathogenesis of Marfan syndrome. Genomics, v.17, n.2, Aug, p.468-75. 1993a.

DIETZ, H. C., D. VALLE, et al. The skipping of constitutive exons in vivo induced by nonsense mutations. Science, v.259, n.5095, Jan 29, p.680-3. 1993b.

DUNNILL, M. S. Quantitative Methods in the Study of Pulmonary Pathology. Thorax, v.17, p.320-28. 1962.

FRISCHMEYER, P. A. e H. C. DIETZ. Nonsense-mediated mRNA decay in health and disease. Hum Mol Genet, v.8, n.10, p.1893-900. 1999.

FUNABA, M., C. M. ZIMMERMAN, et al. Modulation of Smad2-mediated signaling by extracellular signal-regulated kinase. J Biol Chem, v.277, n.44, Nov 1, p.41361-8. 2002.

GAYRAUD, B., D. R. KEENE, et al. New insights into the assembly of extracellular microfibrils from the analysis of the fibrillin 1 mutation in the tight skin mouse. $J$ Cell Biol, v.150, n.3, Aug 7, p.667-80. 2000.

GODFREY, M., V. MENASHE, et al. Cosegregation of elastin-associated microfibrillar abnormalities with the Marfan phenotype in families. Am J Hum Genet, v.46, n.4, Apr, p.652-60. 1990a.

GODFREY, M., S. OLSON, et al. Unilateral microfibrillar abnormalities in a case of asymmetric Marfan syndrome. Am J Hum Genet, v.46, n.4, Apr, p.661-71. 1990b.

GREEN, M. C., H. O. SWEET, et al. Tight-skin, a new mutation of the mouse causing excessive growth of connective tissue and skeleton. Am J Pathol, v.82, n.3, Mar, p.493-512. 1976.

HABASHI, J. P., D. P. JUDGE, et al. Losartan, an AT1 antagonist, prevents aortic aneurysm in a mouse model of Marfan syndrome. Science, v.312, n.5770, Apr 7, p.11721. 2006.

HANAFUSA, H., J. NINOMIYA-TSUJI, et al. Involvement of the p38 mitogen-activated protein kinase pathway in transforming growth factor-beta-induced gene expression. $J$ Biol Chem, v.274, n.38, Sep 17, p.27161-7. 1999. 
HEWETT, D., J. LYNCH, et al. Differential allelic expression of a fibrillin gene (FBN1) in patients with Marfan syndrome. Am J Hum Genet, v.55, n.3, Sep, p.447-52. 1994.

HOCEVAR, B. A., T. L. BROWN, et al. TGF-beta induces fibronectin synthesis through a C-Jun N-terminal kinase-dependent, Smad4-independent pathway. EMBO J, v.18, n.5, Mar 1, p.1345-56. 1999.

HOGAN, A., R. BEDDINGTON, et al. Manipulating the mouse Embryo: a laboratory manual. Cold Spring Harbor, NY: Cold Spring Harbor Laboratory Press. 1994

HOLLISTER, D. W., M. GODFREY, et al. Immunohistologic abnormalities of the microfibrillar-fiber system in the Marfan syndrome. N Engl J Med, v.323, n.3, Jul 19, p.152-9. 1990.

HUTCHINSON, S., A. FURGER, et al. Allelic variation in normal human FBN1 expression in a family with Marfan syndrome: a potential modifier of phenotype? Hum Mol Genet, v.12, n.18, Sep 15, p.2269-76. 2003.

JAVELAUD, D. e A. MAUVIEL. [Transforming growth factor-betas: smad signaling and roles in physiopathology]. Pathol Biol (Paris), v.52, n.1, Feb, p.50-4. 2004.

JUDGE, D. P., N. J. BIERY, et al. Evidence for a critical contribution of haploinsufficiency in the complex pathogenesis of Marfan syndrome. $J$ Clin Invest, v.114, n.2, Jul, p.172-81. 2004.

KAARTINEN, V. e D. WARBURTON. Fibrillin controls TGF-beta activation. Nat Genet, v.33, n.3, Mar, p.331-2. 2003.

KAINULAINEN, K. e L. PELTONEN. Marfan gene discovered. Ann Med, v.23, n.4, Oct, p.395-6. 1991.

KIELTY, C. M., C. BALDOCK, et al. Fibrillin: from microfibril assembly to biomechanical function. Philos Trans R Soc Lond B Biol Sci, v.357, n.1418, Feb 28, p.207-17. 2002.

KIELTY, C. M. e C. A. SHUTTLEWORTH. Fibrillin-containing microfibrils: structure and function in health and disease. Int J Biochem Cell Biol, v.27, n.8, Aug, p.747-60. 1995.

LATTIMER, J. K. Lincoln did not have the Marfan Syndrome; documented evidence. N Y State J Med, v.81, n.12, Nov, p.1805-13. 1981.

LIPSCOMB, K. J., J. CLAYTON-SMITH, et al. Evolving phenotype of Marfan's syndrome. Arch Dis Child, v.76, n.1, Jan, p.41-6. 1997.

LOEYS, B., J. DE BACKER, et al. Comprehensive molecular screening of the FBN1 gene favors locus homogeneity of classical Marfan syndrome. Hum Mutat, v.24, n.2, Aug, p.140-6. 2004.

LOEYS, B., L. NUYTINCK, et al. Genotype and phenotype analysis of 171 patients referred for molecular study of the fibrillin-1 gene FBN1 because of suspected Marfan syndrome. Arch Intern Med, v.161, n.20, Nov 12, p.2447-54. 2001.

LOEYS, B. L., H. C. DIETZ, et al. The revised Ghent nosology for the Marfan syndrome. J Med Genet, v.47, n.7, Jul, p.476-85. 2010. 
MASSAGUE, J. e Y. G. CHEN. Controlling TGF-beta signaling. Genes Dev, v.14, n.6, Mar 15, p.627-44. 2000.

MERKEL, C. A. Geração e análise de um animal "knockout" para a fibrilina-1, o produto gênico envolvido na Síndrome de Marfan. Instituto de Ciência Biomédicas, Universidade de São Paulo, São Paulo, 2006.

MILEWICZ, D. M., J. GROSSFIELD, et al. A mutation in FBN1 disrupts profibrillin processing and results in isolated skeletal features of the Marfan syndrome. $J$ Clin Invest, v.95, n.5, May, p.2373-8. 1995.

MURAISHI, H. [Fundamental of medical image processing with personal computer system--development of Plugins by ImageJ]. Nippon Hoshasen Gijutsu Gakkai Zasshi, v.66, n.3, Mar 20, p.260-4. 2010.

NAKAJIMA, Y., K. MIYAZONO, et al. Immunolocalization of latent transforming growth factor-beta binding protein-1 (LTBP1) during mouse development: possible roles in epithelial and mesenchymal cytodifferentiation. Cell Tissue Res, v.295, n.2, Feb, p.25767. 1999.

NEPTUNE, E. R., P. A. FRISCHMEYER, et al. Dysregulation of TGF-beta activation contributes to pathogenesis in Marfan syndrome. Nat Genet, v.33, n.3, Mar, p.407-11. 2003.

NG, C. M., A. CHENG, et al. TGF-beta-dependent pathogenesis of mitral valve prolapse in a mouse model of Marfan syndrome. J Clin Invest, v.114, n.11, Dec, p.1586-92. 2004.

NIJBROEK, G., S. SOOD, et al. Fifteen novel FBN1 mutations causing Marfan syndrome detected by heteroduplex analysis of genomic amplicons. Am J Hum Genet, v.57, n.1, Jul, p.8-21. 1995.

OTSURU, S., T. J. HOFMANN, et al. Osteopoietic engraftment after bone marrow transplantation: Effect of inbred strain of mice. Exp Hematol, May 3. 2010.

PALZ, M., F. TIECKE, et al. Clustering of mutations associated with mild Marfan-like phenotypes in the $3^{\prime}$ region of FBN1 suggests a potential genotype-phenotype correlation. Am J Med Genet, v.91, n.3, Mar 20, p.212-21. 2000.

PEREIRA, L., K. ANDRIKOPOULOS, et al. Targetting of the gene encoding fibrillin-1 recapitulates the vascular aspect of Marfan syndrome. Nat Genet, v.17, n.2, Oct, p.21822. 1997.

PEREIRA, L., M. D'ALESSIO, et al. Genomic organization of the sequence coding for fibrillin, the defective gene product in Marfan syndrome. Hum Mol Genet, v.2, n.10, Oct, p.1762. 1993.

PEREIRA, L., S. Y. LEE, et al. Pathogenetic sequence for aneurysm revealed in mice underexpressing fibrillin-1. Proc Natl Acad Sci U S A, v.96, n.7, Mar 30, p.3819-23. 1999.

PU, W. T. Identification of a cardiac disease modifier gene using forward genetics in the mouse. PLoS Genet, v.5, n.9, Sep, p.e1000643. 2009.

PYERITZ, R. E. The Marfan syndrome. Am Fam Physician, v.34, n.6, Dec, p.83-94. 1986. 
PYERITZ, R. E. Pleiotropy revisited: molecular explanations of a classic concept. Am J Med Genet, v.34, n.1, Sep, p.124-34. 1989.

PYERITZ, R. E. Marfan syndrome: current and future clinical and genetic management of cardiovascular manifestations. Semin Thorac Cardiovasc Surg, v.5, n.1, Jan, p.11-6. 1993.

PYERITZ, R. E. The Marfan syndrome. Annu Rev Med, v.51, p.481-510. 2000.

RADONIC, T., P. DE WITTE, et al. Losartan therapy in adults with Marfan syndrome: study protocol of the multi-center randomized controlled COMPARE trial. Trials, v.11, p.3. 2010.

RAKYAN, V. K., M. E. BLEWITT, et al. Metastable epialleles in mammals. Trends Genet, v.18, n.7, Jul, p.348-51. 2002.

RAMIREZ, F. e L. PEREIRA. The fibrillins. Int J Biochem Cell Biol, v.31, n.2, Feb, p.2559. 1999.

REINHARDT, D. P., D. R. KEENE, et al. Fibrillin-1: organization in microfibrils and structural properties. J Mol Biol, v.258, n.1, Apr 26, p.104-16. 1996.

ROBINSON, P. N., E. ARTEAGA-SOLIS, et al. The molecular genetics of Marfan syndrome and related disorders. J Med Genet, v.43, n.10, Oct, p.769-87. 2006.

ROBINSON, P. N. e M. GODFREY. The molecular genetics of Marfan syndrome and related microfibrillopathies. J Med Genet, v.37, n.1, Jan, p.9-25. 2000.

RODRIGUEZ-VITA, J., E. SANCHEZ-LOPEZ, et al. Angiotensin II activates the Smad pathway in vascular smooth muscle cells by a transforming growth factor-betaindependent mechanism. Circulation, v.111, n.19, May 17, p.2509-17. 2005.

RUIZ-ORTEGA, M., M. RUPEREZ, et al. Molecular mechanisms of angiotensin IIinduced vascular injury. Curr Hypertens Rep, v.5, n.1, Feb, p.73-9. 2003.

SAHARINEN, J. e J. KESKI-OJA. Specific sequence motif of 8-Cys repeats of TGF-beta binding proteins, LTBPs, creates a hydrophobic interaction surface for binding of small latent TGF-beta. Mol Biol Cell, v.11, n.8, Aug, p.2691-704. 2000.

SAITO, S., H. NISHIMURA, et al. Characterization of mutated protein encoded by partially duplicated fibrillin-1 gene in tight skin (TSK) mice. Mol Immunol, v.36, n.3, Feb, p.169-76. 1999.

SAKAI, L. Y., D. R. KEENE, et al. Fibrillin, a new 350-kD glycoprotein, is a component of extracellular microfibrils. J Cell Biol, v.103, n.6 Pt 1, Dec, p.2499-509. 1986.

SANTOS, E. Desenvolvimento de um modelo animal para a Síndrome de Marfan através da manipulação do genoma do camundongo. Instituto de Ciências Biomédicas, Universidade de São Paulo, São Paulo, 2005.

SCHORDERET, D. F. Using OMIM (On-line Mendelian Inheritance in Man) as an expert system in medical genetics. Am J Med Genet, v.39, n.3, Jun 1, p.278-84. 1991. 
SCHORR, S., K. BRAUN, et al. Congenital aneurysmal dilatation of the ascending aorta associated with arachnodactyly; an angiocardiographic study. Am Heart J, v.42, n.4, Oct, p.610-6. 1951.

SCHRIJVER, I., W. LIU, et al. Cysteine substitutions in epidermal growth factor-like domains of fibrillin-1: distinct effects on biochemical and clinical phenotypes. Am $J$ Hum Genet, v.65, n.4, Oct, p.1007-20. 1999.

SCHRIJVER, I., W. LIU, et al. Premature termination mutations in FBN1: distinct effects on differential allelic expression and on protein and clinical phenotypes. Am $\mathrm{J}$ Hum Genet, v.71, n.2, Aug, p.223-37. 2002.

SCHWARTZ, H. Abraham Lincoln and the Marfan Syndrome. JAMA, v.187, Feb 15, p.473-9. 1964.

SILVERMAN, D. I., K. J. BURTON, et al. Life expectancy in the Marfan syndrome. Am J Cardiol, v.75, n.2, Jan 15, p.157-60. 1995a.

SILVERMAN, D. I., J. GRAY, et al. Family history of severe cardiovascular disease in Marfan syndrome is associated with increased aortic diameter and decreased survival. J Am Coll Cardiol, v.26, n.4, Oct, p.1062-7. 1995b.

SUNAGA, S., K. MAKI, et al. Efficient removal of loxP-flanked DNA sequences in a gene-targeted locus by transient expression of Cre recombinase in fertilized eggs. Mol Reprod Dev, v.46, n.2, Feb, p.109-13. 1997.

SWEET, A., R. P. ERICKSON, et al. A potential animal model for studying CF heterozygote advantage: genetic variation in theophylline-inducible colonic chloride currents among inbred strains of mice. Biochem Med Metab Biol, v.47, n.1, Feb, p.97102. 1992.

TAIPALE, J., J. SAHARINEN, et al. Extracellular matrix-associated transforming growth factor-beta: role in cancer cell growth and invasion. Adv Cancer Res, v.75, p.87-134. 1998.

VAINZOF, M., M. R. PASSOS-BUENO, et al. Immunological methods for the analysis of protein expression in neuromuscular diseases. Methods Mol Biol, v.217, p.355-78. 2003.

WHEELER, F. C., L. FERNANDEZ, et al. QTL mapping in a mouse model of cardiomyopathy reveals an ancestral modifier allele affecting heart function and survival. Mamm Genome, v.16, n.6, Jun, p.414-23. 2005.

WHITEMAN, P. e P. A. HANDFORD. Defective secretion of recombinant fragments of fibrillin-1: implications of protein misfolding for the pathogenesis of Marfan syndrome and related disorders. Hum Mol Genet, v.12, n.7, Apr 1, p.727-37. 2003.

YANG, T., Y. G. HUANG, et al. Influence of genetic background and gender on hypertension and renal failure in COX-2-deficient mice. Am J Physiol Renal Physiol, v.288, n.6, Jun, p.F1125-32. 2005.

ZANGALA, T. Isolation of genomic DNA from mouse tails. J Vis Exp, n.6, p.246. 2007.

ZHANG, H., W. HU, et al. Developmental expression of fibrillin genes suggests heterogeneity of extracellular microfibrils. J Cell Biol, v.129, n.4, May, p.1165-76. 1995. 
ZHANG, Y. E. Non-Smad pathways in TGF-beta signaling. Cell Res, v.19, n.1, Jan, p.128-39. 2009. 
VIII. ANEXO 